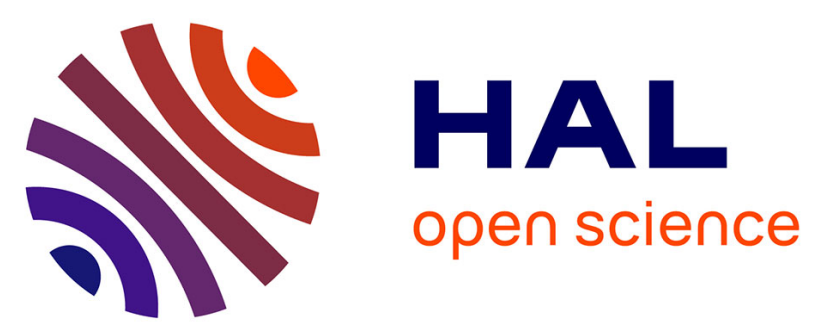

\title{
Effect of flow forecasting quality on benefits of reservoir operation? a case study for the Geheyan reservoir (China)
}

\author{
X. Dong, C. M. Dohmen-Janssen, M. Booij, S. Hulscher
}

\section{- To cite this version:}

X. Dong, C. M. Dohmen-Janssen, M. Booij, S. Hulscher. Effect of flow forecasting quality on benefits of reservoir operation? a case study for the Geheyan reservoir (China). Hydrology and Earth System Sciences Discussions, 2006, 3 (6), pp.3771-3814. hal-00298805

\section{HAL Id: hal-00298805 \\ https://hal.science/hal-00298805}

Submitted on 13 Dec 2006

HAL is a multi-disciplinary open access archive for the deposit and dissemination of scientific research documents, whether they are published or not. The documents may come from teaching and research institutions in France or abroad, or from public or private research centers.
L'archive ouverte pluridisciplinaire HAL, est destinée au dépôt et à la diffusion de documents scientifiques de niveau recherche, publiés ou non, émanant des établissements d'enseignement et de recherche français ou étrangers, des laboratoires publics ou privés. 
Hydrol. Earth Syst. Sci. Discuss., 3, 3771-3814, 2006 www.hydrol-earth-syst-sci-discuss.net/3/3771/2006/

(C) Author(s) 2006. This work is licensed under a Creative Commons License.
Hydrology and Earth System Sciences Discussions
Papers published in Hydrology and Earth System Sciences Discussions are under open-access review for the journal Hydrology and Earth System Sciences

HESSD

3, 3771-3814, 2006

Effect of flow forecasting quality

on benefits of reservoir operation

X. Dong et al.

\section{Effect of flow forecasting quality on benefits of reservoir operation - a case study for the Geheyan reservoir (China)}

X. Dong ${ }^{1,2,{ }^{*}}$, C. M. Dohmen-Janssen ${ }^{3}$, M. Booij ${ }^{3}$, and S. Hulscher ${ }^{3}$

${ }^{1}$ China Three Gorges Project Corporation, Yichang, Hubei Province, China

${ }^{2}$ Wuhan University, Wuhan, Hubei Province, China

${ }^{3}$ University of Twente, Enschede, The Netherlands

*now at: China Three Gorges University, Yichang, Hubei Province, China

Received: 6 November 2006 - Accepted: 21 November 2006 - Published: 13 December 2006 Correspondence to: X. Dong (xhdong @ctgu.edu.cn)

\section{Title Page}

Abstract Introduction

Conclusions

Tables References Figures

14 $>1$

4

Back

Full Screen / Esc

Printer-friendly Version

Interactive Discussion 


\section{Abstract}

This paper presents a methodology to determine the effect of flow forecasting quality on the benefits of reservoir operation. The benefits are calculated in terms of the electricity generated, and the quality of the flow forecasting is defined in terms of lead

5 time and accuracy of the forecasts. In order to determine such an effect, an optimization model for reservoir operation was developed which consists of two sub-models: a long-term (monthly) and a short-term (daily) optimization sub-model. A methodology was developed to couple these two sub-models, so that both short-term benefits (time span in the order of the flow forecasting lead time) and long-term benefits (one year) were considered and balanced. Both sub-models use Discretized Dynamic Programming (DDP) as their optimization algorithms. The Geheyan reservoir on the Qingjiang River in China was taken as case study. Observed (from the 1997 hydrological year) and forecasted flow series were used to calculate the benefits. Forecasted flow series were created by adding noises to the observed series. Different magnitudes of 15 noise reflected different levels of forecasting accuracies. The results reveal, first of all, a threshold lead time of 33 days, beyond which further extension of the forecasting lead time will not lead to a significant increase in benefits. Secondly, for lead times shorter than 33 days, a longer lead time will generally lead to a higher benefit. Thirdly, a perfect inflow forecasting with a lead time of 4 days will realize $87 \%$ of the theoretical maximum electricity generated in one year. Fourthly, for a certain lead time, more accurate forecasting leads to higher benefits. For inflow forecasting with a fixed lead time of 4 days and different forecasting accuracies, the benefits can increase by 5 to $9 \%$ compared to the actual operation results. It is concluded that the definition of the appropriate lead time will depend mainly on the physical conditions of the basin and on theoretical upper limit for the extension of forecasting lead time. Criteria for the appropriate forecasting accuracy for a specific feasible lead-time should be defined from the benefit-accuracy relationship, starting from setting a preferred benefit level, in terms

HESSD

3, 3771-3814, 2006

\section{Effect of flow forecasting quality on benefits of reservoir operation}

X. Dong et al.

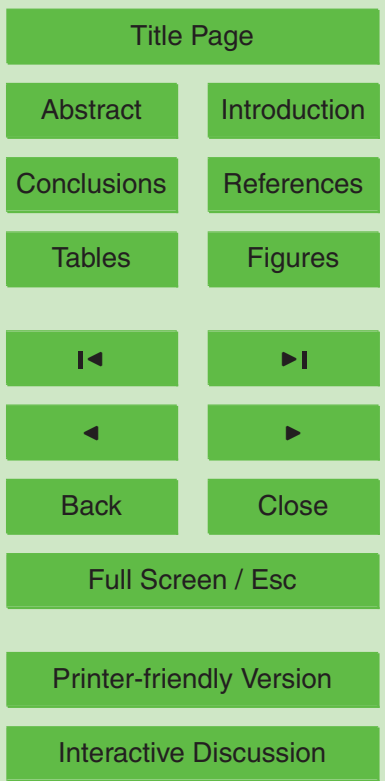

EGU 
of percentage of the theoretical maximum. Inflow forecasting with a higher accuracy does not always increase the benefits, because these also depend on the operation strategies of the reservoir.

\section{Introduction}

5 Flow forecasting plays an important role in managing water resources systems. This is especially the case for reservoirs, because streamflows are the major inputs into the reservoirs. Obtaining high-quality streamflow forecasts and making efficient use of these forecasts make it possible to obtain maximum benefit from the forthcoming water. Here, the quality of flow forecasting is quantified in terms of lead time and accuracy.

10 The lead time of flow forecasting is the time interval between the issuing of the forecast and the occurrence of the forecasted flow event (Maidment, 1992, chapter 26). The accuracy of flow forecasting can be defined as the difference between the forecasted and the actual flow (Maidment, 1992, chapter 26).

It is intuitively clear that higher-quality flow forecasting yields higher benefits for 15 reservoir operation. For example, flow forecasts with longer lead times enable optimizations over longer time horizons. This leads to a better balance between the immediate benefits and the potential future benefits, thus increasing the total benefit. In addition, with more accurate flow forecasting being available, the operations can be more precise and can be taken with higher confidence, which increases the benefits and avoids potential damage resulting from responding to incorrect forecasts. Therefore, flow forecasts with higher quality are always appreciated by reservoir managers.

It can also be intuitively foreseen that the increase of the quality of flow forecasting will never be unlimited. This may be because of technical and physical limitations or because the costs arising from improving the forecasts exceed the benefits obtained from the improvements.

Therefore, a balance needs to be reached between what we want to obtain and what is possible to obtain in reality. In order to reach this balance, a benefit analysis of
HESSD

3, 3771-3814, 2006

Effect of flow forecasting quality on benefits of reservoir operation

X. Dong et al.

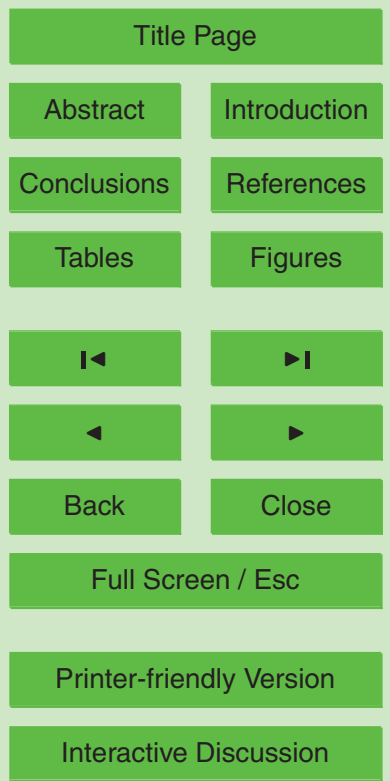

EGU 
flow forecasting is necessary, i.e., an investigation of the effect of the quality of flow forecasting on the benefits of reservoir operation.

In view of above facts, the objective of the research described in this paper is therefore, to determine how a benefit analysis for reservoir operation can be carried out in 5 such a way that it provides requirements for the quality of flow forecasting, in terms of lead time and accuracy.

The resulting benefit-lead time-accuracy relationships will form the basis for determining the appropriate quality of flow forecasting (appropriate lead time and accuracy) for reservoir operation. Within this context, the purpose of flow forecasting is oriented 10 towards improving the operation of a reservoir for a specific objective. For the reservoir that will be studied (which will be described in Sect. 2), this will be to maximize hydropower generation, under the constraints arising from the requirements of flood defence and navigation. In order to apply a hydrological model appropriately to produce flow forecasting results with required quality, further research need to be done on, 15 for example, how to handle hydrological process(es) in the hydrological model appropriately to produce flow forecasting with desired quality. An example of such research has been published recently (Dong et al., 2005). And a detail description of such an approach to determine the appropriate flow forecasting for reservoir operation was given by Dong (2005).

20 A number of research groups have evaluated the effect of flow forecasting quality on benefits of reservoir operation.

Yeh et al. (1978, 1980, 1982) investigated the benefits of short-term and long-term flow forecasting with varying accuracies on reservoir operation separately. For evaluating the benefits obtained from the short-term (1 to 7 days) flow forecasting, they 25 used a hybrid algorithm called Linear Programming and Dynamic Programming (LPDP) (Becker et al., 1976). For evaluating the benefits obtained from the long-term (1 to 12 months) flow forecasting, only a simulation model was used. The results showed that, for inflow forecasting with 100\% accuracy, the benefits (average annual electricity generated) increase roughly linearly with the extension of lead times, at a rate of

HESSD

3, 3771-3814, 2006

\section{Effect of flow forecasting quality on benefits of reservoir operation}

X. Dong et al.

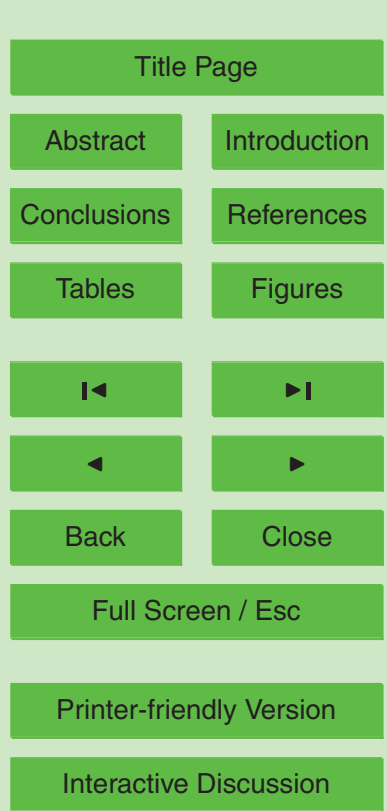


$0.5 \% /$ day (up to 7 days) (Yeh et al., 1978). The implementation of long-term (monthly) flow forecasting also increased the benefits. A long-term flow forecasting with an error of 0.5 (assumed standard deviation normalized to observed flows) can increase the power output by $4 \%$, compared with the operation without the long-term flow forecast5 ing (Yeh et al., 1980, 1982).

Burgers and Hoshi (1978) evaluated the benefits obtained from forecasting the total seasonal runoff volume for reservoir operation. Instead of a real reservoir, two hypothetic multiple-purpose reservoirs with different storage capacities were examined. A so-called Linear Decision Rule (LDR) (ReVelle et al., 1969) - within which linear 10 programming was imbedded as its optimization algorithm - was used to simulate the operation of these two hypothetic reservoirs. The results showed an increase in the total benefits, and the increase was higher when higher flow volumes were anticipated.

Hamlet et al. (2002) evaluated the economic value (in terms of hydropower generated) of monthly streamflow forecasts with a lead time up to one year. A modified 15 heuristic reservoir operation model based on rule curves was used to assess the benefit (Hamlet and Lettenmaier, 1999). The results showed that the use of this long-term flow forecasting increased the non-firm energy production (the production of the "extra" electricity, i.e., the electricity generated in addition to the required electricity that has to be delivered/produced as specified/agreed in purchase contracts) from the major Columbia river hydropower dams in the United States by as much as $30 \%$ compared to the status quo output.

Georgakakos (1989) assessed the benefits of streamflow forecasting for three reservoir systems. Four statistical streamflow models of increasing forecasting ability were used and coupled with a stochastic control method to optimize reservoir operation 25 (Georgakakos and Marks, 1987; Georgakakos, 1989). The forecasting ability of the models was simulated by using different values for the variance of the forecasting error in the models: the lower the variance, the better the model. The benefits for the systems were evaluated in terms of energy generation and flood and drought prevention. The results indicated that better forecasting models (smaller variance) did improve the

HESSD

3, 3771-3814, 2006

\section{Effect of flow forecasting quality on benefits of reservoir operation}

X. Dong et al.

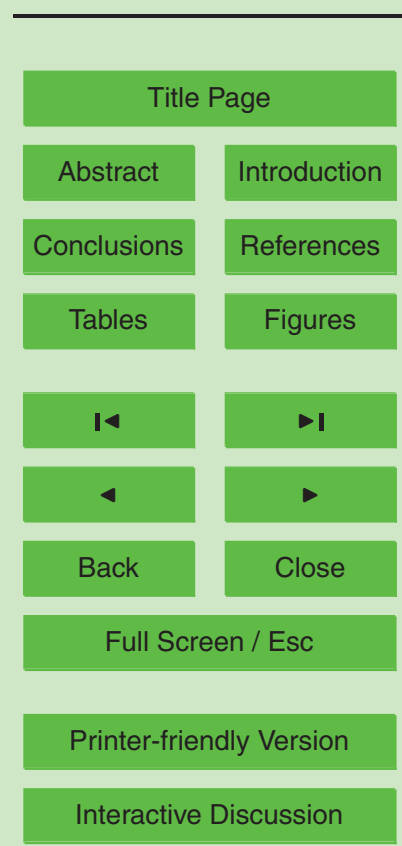


reservoir operation, but this effect differed for different reservoir systems, and ranged from quite substantial to minimal.

With regard to the above methods used to analyse the benefits arising from the flow forecasting on reservoir operation, the following three research gaps are identified:

1. The relationship between long-term and short-term optimization models has not yet been considered in analysing benefits obtained from reservoir operation. The aforementioned studies conducted the long-term and short-term optimizations separately. However, the clarification of this relationship is especially important for reservoir operation because the choice of operation strategy should be based not only upon the short-term benefits but also on the potential (possibly greater) benefits obtained in the long term. Therefore, developing a mechanism to couple the long-term and short-term optimization models is necessary.

2. Longer lead times in flow forecasting generally bring greater benefits. As the benefit will never grow infinitely with the extension of lead time, an interesting question still remains to be answered: what is the upper limit of the extension of the lead time for a specific reservoir, beyond which the obtained extra benefits will no longer be worth the effort? Clarifying this question will set the upper boundary for the extension of forecasting lead time, therefore eliminate unnecessary effort in trying to extend the lead time.

3. It is generally recognized that flow forecasting with higher quality (longer lead time and higher accuracy) will result in greater benefits. The aforementioned studies, however, did not conduct the evaluation in a statistical manner, and the uncertainty of this benefit - lead time - accuracy relationships has not yet been estimated. Therefore, this relationship needs to be clarified to determine if a

HESSD

3, 3771-3814, 2006

\section{Effect of flow forecasting quality \\ on benefits of reservoir operation}

X. Dong et al.

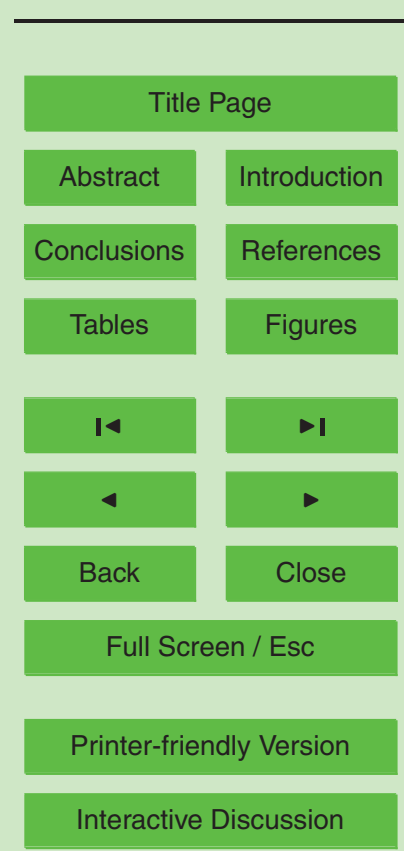


1. How to couple the long-term and short-term optimization models so that their benefits are well balanced and fully assessed?

2. Is there a limit of the extension of the lead time of flow forecasting from the viewpoint of the extra benefit obtained? If so, how to quantify this limit?

3. What is the relationship between benefits and flow forecasting quality? Does a higher quality forecasting certainly lead to higher benefits?

The outline of this paper is as follows. Section 2 describes the reservoir used as the case study in this research. Then in Sect. 3, our approach to analyze the benefit leadtime - accuracy relationship will be described. In Sect. 4, a methodology to couple

10 the long-term and short-term optimization model is developed. In Sect. 5, a detailed description of the optimization model is given. Section 6 presents the results, which are discussed in Sect. 7. The paper ends with conclusions in Sect. 8.

\section{Case study of Geheyan reservoir}

The methodology that is developed, is applied to the Geheyan Reservoir. This reservoir 15 is located on one of the tributaries of the Changjiang River (Yangtze): the Qingjiang River. Its geographic location in China is shown in Fig. 1. The area of the river basin upstream of the Geheyan Reservoir is $14430 \mathrm{~km}^{2}$. The average discharge at the dam site is $400 \mathrm{~m}^{3} / \mathrm{s}$. The average annual precipitation in this area is $1400 \mathrm{~mm}$. The average annual flow volume at the dam site is $12.65 \times 10^{9} \mathrm{~m}^{3}$.

20 The Geheyan Reservoir is constructed to utilize potential benefits for hydropower, flood defence, navigation, in which hydropower generation is its main purpose. Figure 2 shows the major characteristic water levels and storage zones of the reservoir. The reservoir started storing water on 10 April 1993. On 30 November 1994, all four generators started generating electricity. The power plant of the dam was installed with 25 four generators, each with a capacity of 300 Megawatt (MW). In total, this power plant

\section{Effect of flow forecasting quality on benefits of reservoir operation}

X. Dong et al.

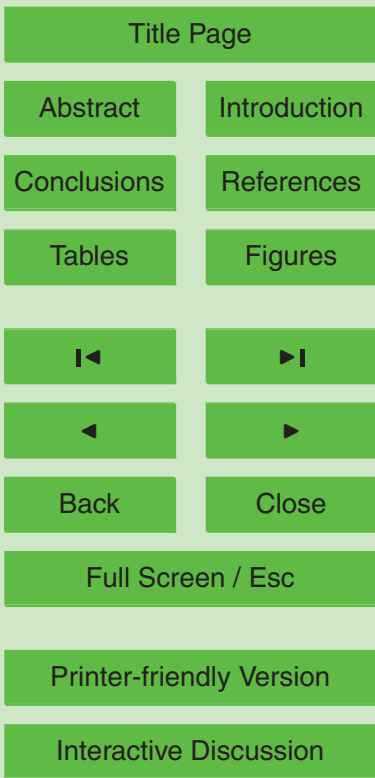

EGU 
is able to afford electricity for a city with a population of 2 million. The maximum discharge through the turbine of each generator is $325 \mathrm{~m}^{3} / \mathrm{s}$. The average power output of the power plant is $30.4 \mathrm{kWh}$ (kilowatt · hour). The firm output under a design guarantee rate of $92 \%$ is $180 \mathrm{MW}$. The design guarantee rate of the power plant is the probability $5(92 \%)$ that the power output is higher than the firm output (180 MW). The firm output is the average power output during the dry season. The values of the firm output and design guarantee rate are stipulated by the Qingjiang Hydropower Development Corporation and the Changjiang Water Resources Committee (QHDC and CWRC, 1998).

The wet season in the Qingjiang River basin extends from May to October and most 10 big flooding events take place during this period. Therefore, the local water authority defined the first of May as the start of the hydrological year. A hydrological year covers for a time horizon from the end of the dry season of the year considered to the end of the dry season of the next year (Ministry of Water Resources of People's Republic of China, 1999). It consists of a complete hydrological cycle - one dry season and one wet season. It also covers a complete reservoir operation cycle: the pool level starts rising from the dead-water level at the end of the dry season, and falls back to the dead-water level after one year of operation. Ideally, the reservoir is depleted from the beginning of the dry season (1 November) to the dead-water level before the first of May, and from then on, refilled to the normal pool level at the end of the flooding season.

\section{Benefit - lead time - accuracy relationship}

Determining the benefit - lead time - accuracy relationship is carried out by calculating the benefits arising from flow forecasts with different levels of quality for reservoir operation. To calculate the maximum benefits, an optimization model is used, which consists of 2 sub-models: a long-term and a short-term optimization sub-model. The optimization time horizon of the long-term sub-model is equal to the lead time of the long-term flow forecasting (one year); the optimization time step is one month. The
HESSD

3, 3771-3814, 2006

\section{Effect of flow forecasting quality on benefits of reservoir operation}

X. Dong et al.

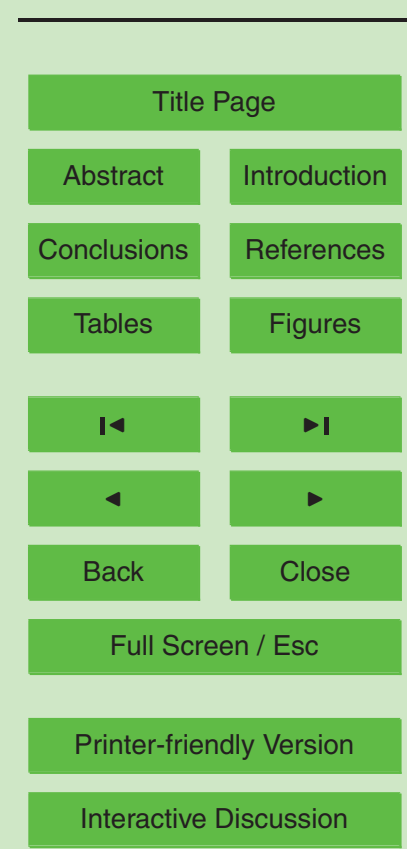

EGU 
optimization time horizon of the short-term sub-model is equal to the lead time of the short-term flow forecasting (varying from one to about 7 days); the optimization time step is one day.

A methodology is developed to couple the two sub-models, to balance the benefits 5 obtained from the present and from future time periods (so that a gross overall maximum benefit can be obtained). This coupling method will be introduced in Sect. 4 .

To determine the relationship between benefits and the quality of flow forecasting, forecasted flow series with different levels of forecasting quality should be used as input into the optimization model. Such forecasted flow series are difficult to obtain. There10 fore, we use a model to generate forecasted series based on observed flow series. The observed flow data of the hydrological year 1997 (see Fig. 7a) were selected as example data for such a benefit analysis. It is necessary to calculate the benefits of reservoir operation over a complete hydrological year, because the reservoir operation in the wet and dry seasons need to be considered collectively in order to obtain an 15 annual gross maximum benefit. The flow data in hydrological year 1997 is selected because of two reasons:

1. There was only one large flooding event in this hydrological year. This may make it easier to answer the research question two (i.e., to identify the limit of the extension of the lead time) than selecting other years with multiple large flooding events.

2. The peak discharge $\left(15400 \mathrm{~m}^{3} / \mathrm{s}\right.$, with a return period of 25 years (QHDC and CWRC,1998)) in this hydrological year exceeds the maximum allowable discharge $\left(13000 \mathrm{~m}^{3} / \mathrm{s}\right)$ of the downstream channel of the reservoir. Therefore selecting this hydrological year for case study can validate the effectiveness of the optimization the maximum release to be less than the maximum allowable discharge.

Next, the relationships between lead time and benefit and between flow forecasting accuracy and benefit are determined:

HESSD

3, 3771-3814, 2006

\section{Effect of flow forecasting quality on benefits of reservoir operation}

X. Dong et al.

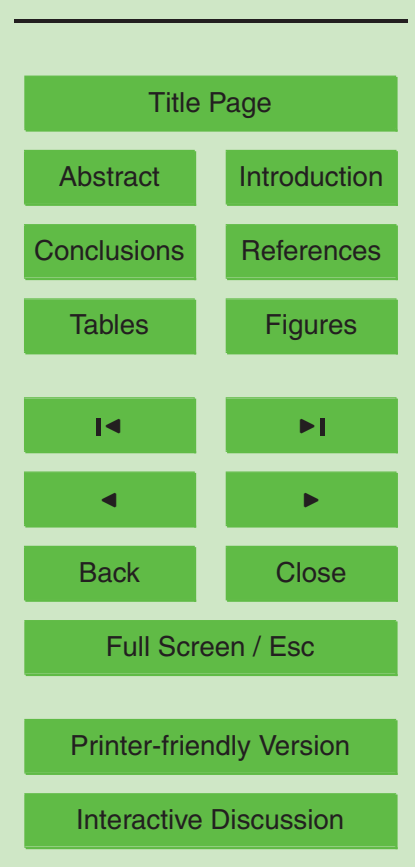

EGU 
1. In order to determine the relationship between lead time and benefit, the observed flow series of the hydrological year 1997 are used. The input data for the longterm sub-model are the monthly averaged series of the observed flow series. The input data for the short-term sub-model are cut off from the observed flow series with different length of time steps, which equals the lead times of the short-term flow forecastings.

2. In order to determine the relationship between flow forecasting accuracy and benefit, a maximum feasible lead time (here 4 days) was selected to demonstrate the methodology. Different levels of noise were added to the observed flow series to represent different levels of accuracy of the short-term forecasting series. Such a way of generating forecasted flow series is accomplished, using the following equation (De Kok et al., 2004):

$Q_{t}=Q_{t}^{o}+\beta_{t}$

$\beta_{t}=\delta_{t} \varphi Q_{t}^{o}+\alpha \beta_{t-1}$

15 where, $Q_{t}$ is the forecasted flow at time step $t$ (which is artificially generated by using Eq. 1); $Q_{t}^{o}$ is the observed flow at time step $t ; \beta_{t}$ is the noise added to the observed flow series; $\delta_{t}$ is a random variable drawn from an uniform distribution in the interval $[-1,+1] ; \varphi$ is the relative absolute error of forecasted $Q_{t}$ against observed flow $Q_{t}^{o}$ at time step $t$, i.e., $\varphi=\left|Q_{t}-Q_{t}^{o}\right| / Q_{t}^{o} ; \alpha$ is the autocorrelation coefficient of the difference 20 $Q_{t}-Q_{t}^{o}$. The difference $Q_{t}-Q_{t}^{o}$ measures the accuracy of the forecasting at time step $t$. The coefficient $\alpha$ is included to represent the fact that the forecasting error at a certain time step is not completely random. It is partly related to the error in the forecast of the previous time step. As a rule of thumb, $\varphi+\alpha$ should be less than 1 (De Kok et al., 2004).

25 The relative absolute error $\varphi$ is a local bias of forecasted against the observed flow, which was used to generate forecasted flow series of different accuracies. The value of $\varphi$ ranges from $40 \%$ to zero, with the latter implying a perfect forecast of the flow series.

HESSD

3, 3771-3814, 2006

\section{Effect of flow forecasting quality on benefits of reservoir operation}

X. Dong et al.

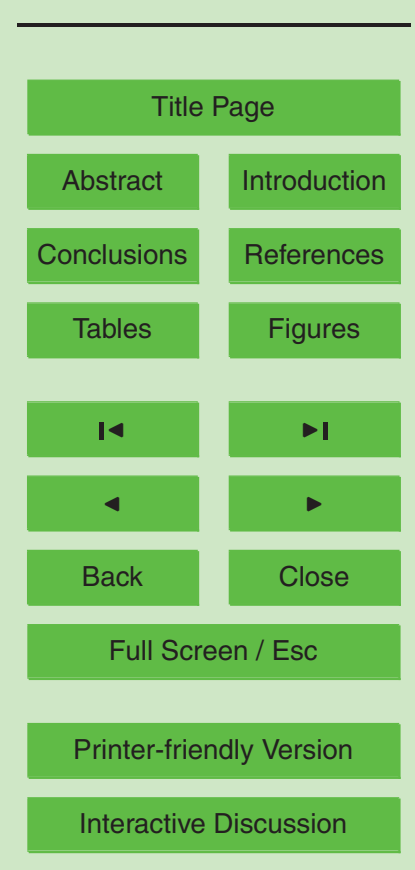

EGU 
$\varphi$ is used here to generate individual forecasted flows. In order to quantify the average forecasting error along a certain time span, the Relative Mean Absolute Error (RMAE) is used as an index to measure the accuracy of the forecasting. In addition, another well-known index, the Nash-Sutcliffe coefficient $\left(R_{N S}\right)$ (Nash and Sutcliffe, 1970), 5 is also used. Their definitions are as follows:

$$
\begin{aligned}
& R_{N S}=1-\frac{\sum_{t=1}^{N}\left(Q_{t}-Q_{t}^{o}\right)^{2}}{\sum_{t=1}^{N}\left(Q_{t}^{o}-\overline{Q_{t}^{o}}\right)^{2}} \\
& \mathrm{RMAE}=\frac{\sum_{t=1}^{N}\left|Q_{t}-Q_{t}^{o}\right|}{\sum_{t=1}^{N} Q_{t}^{o}}
\end{aligned}
$$

where $Q_{t}$ is the forecasted flow at time step $t ; Q_{t}^{o}$ is the observed flow at time step $t$; $N$ is the total number of observations; $\overline{Q_{t}^{o}}$ is the mean of observed flow series. The 10 Nash-Sutcliffe coefficient $R_{N S}$ defines the efficiency of a hydrological model. It ranges from minus infinity to one, with higher values indicating better agreement between forecasted and observed discharges. RMAE measures the relative absolute error of forecasted series. It ranges from zero to positive infinity, with lower values indicating better forecasting performance. It provides a different way of evaluating the forecasting accuracy, other than correlation-based measures like $R^{2}$. Such a simultaneous utilization of these two types of measures follows from the recommendation of Legates and McCabe (1999).

Once the forecasted flow series are generated by using Eq. (1), the corresponding $R_{N S}$ and RMAE values will be calculated. Next, the benefits obtained from each 20 generated series are optimized to determine the $R_{N S}$ - benefit and RMAE - benefit relationships.

\section{HESSD}

3, 3771-3814, 2006

\section{Effect of flow forecasting quality on benefits of reservoir operation}

X. Dong et al.

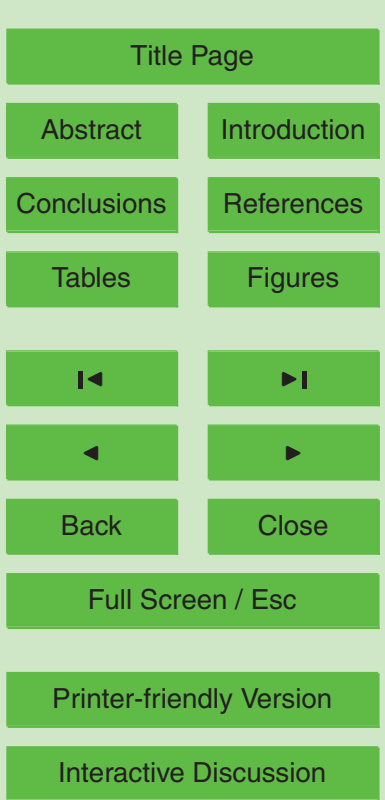

EGU 
All forecasted flow series were input into the optimization model to simulate the corresponding benefits and, therefore, to determine the benefit - accuracy relationship. Lead times longer than 4 days will not be feasible (or quite unreliable) in reality and therefore were not dealt with. The same methodology can be applied to study the ben5 efit - accuracy relationship with lead times shorter than this maximum feasible lead time.

\section{A coupled long-term and short-term optimization model}

Reservoir optimization is conducted by a trade-off evaluation of the benefits obtained from releasing water in the current period and the benefits obtained from storing the 10 water for future use. This trade-off evaluation is performed in both long-term and shortterm sub-models. In addition, a bridge needs to be built between the long-term and short-term sub-models, so that the short-term optimization is guided under the longterm optimization results, and this trade-off evaluation is extended from the short-term to the long-term time horizon. We developed a coupling method to form the bridge 15 between the long-term and short-term sub-models. This method has a hierarchical structure which is similar to the one used by Karamouz et al. (2003).

Figure 3 illustrates the structure of this method, in which the optimization of hydropower reservoir operation consists of two steps: (1) long-term optimization over a one year time horizon on a monthly time step; (2) short-term optimization over a time horizon equal to the lead time of the short-term flow forecasting, on a daily time step.

The purpose of the long-term optimization model is to optimize the averaged monthly releases from the reservoir, and propose the optimal water level reached at the end of each month. The input to this sub-model is the average monthly flow to the reservoir. It is derived from historical records, i.e., the observed monthly flow series from 1951 25 to 1990 . The proposed monthly water level is then interpolated into daily water levels, and used as the guideline for the short-term optimization model.

The input into the short-term optimization model is the daily short-term flow forecast-
HESSD

3, 3771-3814, 2006

\section{Effect of flow forecasting quality on benefits of reservoir operation}

X. Dong et al.

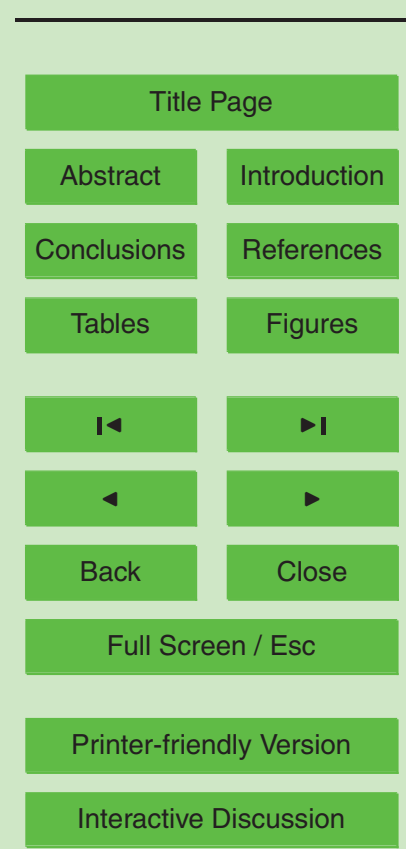


ing into the reservoir. The outputs are the optimal daily reservoir releases and water levels. The short-term optimization is carried out under the guidance of the long-term optimization results. The resulting daily releases and water levels enable the calculation of the benefits obtained from short-term flow forecasting with different levels of 5 forecasting qualities (different lead times and accuracies).

How the long-term optimization results guide the short-term optimization procedure is illustrated in Fig. 4.

Figure $4 a$ presents the monthly water levels optimized from the long-term optimization model and the actual water levels optimized by the coupled long-term and short10 term optimization models. Figure $4 \mathrm{~b}$ zooms into part of Fig. 4a, which demonstrates how this coupling works. At time step 1, the initial water level Hinit(1) is the actual water level at the beginning of a hydrological year (the first of May). If the lead time of the short-term flow forecasting is set to $T^{\prime}$, the terminal water level of the first cycle of the short-term optimization (Hterm(1)) is picked up from the long-term optimization 15 results (daily water levels interpolated from the monthly water levels) at time step $T^{\prime}$. Then the forecasted flow series are introduced into the short-term optimization model, and the optimal releases and water levels from time step 1 to time step $T^{\prime}$ are calculated. Only the proposed optimal release of the first time step is used to calculate the actual water level at the end of the first time step based on the observed flow $\left(Q_{t}^{O}\right)$.

20 The actual water level at the end of the first time step will probably be different from the water level obtained from the long-term optimization. The benefit obtained from the operation during the first time step can be calculated based on the optimal releasing policy and the actual water levels at the beginning and at the end of the time step. The actual water level at the end of the first time step is also the initial state of the second optimization cycle, which is marked as Hinit(2) in Fig. 4(b). The optimization cycle will proceed iteratively to the end of the optimization time horizon: one hydrological year (from the first of May to the end of April of the following year).

For each optimization cycle, the initial water level is the actual water level, and the terminal water level is the water level interpolated from the monthly optimization result.

HESSD

3, 3771-3814, 2006

\section{Effect of flow forecasting quality on benefits of reservoir operation}

X. Dong et al.

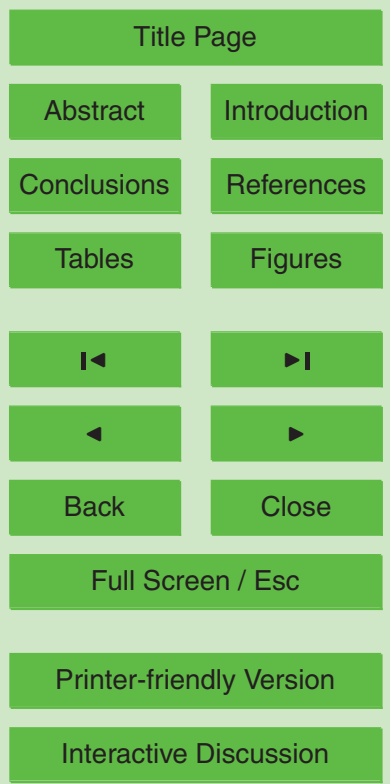

EGU 
This implies that after the operation of one optimization cycle, the water level should be able to fall back to the water level proposed by the long-term optimization model. In this way, the results of the long-term optimization model form the guidelines for the shortterm optimization model, and both long-term and short-term benefits are considered 5 simultaneously.

\section{Details of the optimization model}

Both long-term and short-term optimization sub-models use Discretized Dynamic Programming (DDP) as their optimization algorithm. It is called "discretized", because the whole optimization time horizon is discretized into a series of consecutive time steps.

10 The calculation procedure of the DDP algorithm is given in Fig. 5, which is divided into seven steps.

1) Define stages, select state and decision variables

The time steps are the stages of the optimization model. In the long-term sub-model, one month is considered as one time step. The time span of one long-term optimization cycle is one hydrological year. The total number of time steps (denoted as $T$ ) of the long-term optimization cycle is 12 (months). Individual time steps are denoted as $\mathrm{t}$. In the short-term sub-model, one day is defined as one time step. Each short-term optimization cycle is performed in the time span of the lead time (denoted as $T^{\prime}$, in days) of the short-term flow forecasting. Therefore, the time horizon of a short-term optimization cycle is equal to $T^{\prime}$. The total number of optimization cycles in the hydrological year considered is: $T=365-T^{\prime}+1$.

The water level $H_{t}$ in the reservoir indicates the state of the reservoir at the beginning of time step $t$. Therefore, the water level $H_{t}$ is defined as the state variable. For a complete cycle of a long-term optimization, the beginning water level of the reservoir is the actual water level at the beginning of the hydrological year considered. In this

HESSD

3, 3771-3814, 2006

Effect of flow forecasting quality

on benefits of reservoir operation

X. Dong et al.

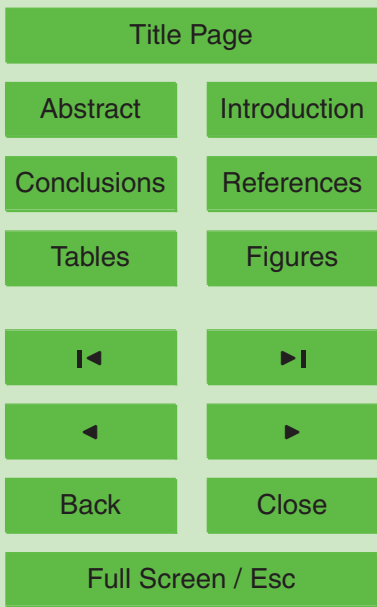

Printer-friendly Version

Interactive Discussion 
case, it is $174.6 \mathrm{~m}$ at the beginning of the 1997 hydrological year. At the end of the hydrological year, the water level is expected to reach the dead water level $(160 \mathrm{~m})$. For each short-term optimization cycle, the beginning water level is the actual water level resulting from previous short-term operations; the ending water level is the one 5 picked up from the optimal water level trajectory calculated by the long-term sub-model (see Fig. 4).

The release $R_{t}$ during time step $\mathrm{t}$ is the most direct measure that can influence the state of the reservoir during time step $t$. Therefore, the release $R_{t}$ is defined as the only decision variable.

\section{2) Discretize the water level space and release space}

The water level between the normal pool level $(200 \mathrm{~m})$ and the dead water level $(160 \mathrm{~m})$ is defined as the water level space denoted as $H^{\text {space }}$. $H^{\text {space }}$ is divided into equally spaced intervals of $0.08 \mathrm{~m}$.

The total collection of all feasible releases is defined as the release space, denoted as $R^{\text {space }}$. $R^{\text {space }}$ is also divided into equally spaced intervals. The upper and lower limits of $R^{\text {space }}$ are set by the following two types of constraints:

(1) Maximum release $\left(R^{\max }\right)$ because of flood defence requirements and minimum release $\left(R^{\mathrm{min}}\right)$ for the purposes of navigation, irrigation, water supply, recreation, fishing, wild life protection, etc.:

$20 R^{\min } \leq R_{t} \leq R^{\max }$

(2) Maximum $\left(R^{e-\max }\right)$ and minimum $\left(R^{e-\min }\right)$ discharge through the turbines:

$R^{e-\min } \leq R_{t}^{e} \leq R^{e-\max }$

where $R_{t}$ is the total release from the reservoir during time step $t$, and $R_{t}^{e}$ is the part through the turbines. For the Geheyan reservoir considered in this research, $R^{\min }=150 \mathrm{~m}^{3} / \mathrm{s}, R^{\max }=13000 \mathrm{~m}^{3} / \mathrm{s}, R^{e-\min }=100 \mathrm{~m}^{3} / \mathrm{s}, R^{e-\max }=1300 \mathrm{~m}^{3} / \mathrm{s}$.

HESSD

3, 3771-3814, 2006

Effect of flow forecasting quality on benefits of reservoir operation

X. Dong et al.

\section{Title Page}

Abstract Introduction

Conclusions

Tables References Figures

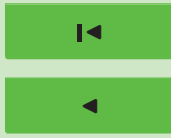
$\rightarrow$

Back

Close

Full Screen / Esc

Printer-friendly Version

Interactive Discussion 
The storage volume $\left(S_{t}\right)$ of the reservoir at the beginning of time step $t$ can also be used as the state variable instead of $H_{t}$. The latter is used here to ease the calculation of water head. In any case, $H_{t}$ and $S_{t}$ can be easily converted into each other by the storage - water level relationship presented by function $f^{S H}$ :

$5 S_{t}=f^{S H}\left(H_{t}\right)$

$S_{t}$ is used as a transition variable to calculate the influences of the inflow into (and outflow out of) the reservoir on the water level. The total collection of all feasible storages is called the storage space, denoted as $S^{\text {space }}$.

3) Construct objective function

10 The major task of the optimization algorithm is to find an optimal water level trajectory (and correspondingly, an optimal release strategy), which can bring maximum benefit in terms of the electricity generated. Therefore, the objective function is formulated as:

$B^{\max }=\max \left\{\sum_{t=1}^{T}\left(b_{t}\right)\right\}=\max \left\{\sum_{t=1}^{T} \eta g R_{t}^{e}\left(\overline{H_{t}}-\overline{h_{t}}\right)\right\}$

In this equation, $B^{\max }$ is the maximum overall benefit. $b_{t}$ is the step benefit obtained 15 in time step $t . T$ is the total number of time steps of an optimization cycle. For a longterm optimization cycle, $T$ is 12 (months); whereas for a short-term optimization cycle, $T=T^{\prime}$ (days). $\eta$ is the efficiency of the hydropower plant, $\eta=\eta_{1} \times \eta_{2} \times \eta_{3}$ (Zhou et al., 1997), with $\eta_{1}$ the efficiency of turbines, $\eta_{2}$ the efficiency of the generators and $\eta_{3}$ the efficiency of the transmission mechanisms. $\eta$ is a varying coefficient according to the is taken for such a large-scale hydropower plant (total installed capacity greater than $250 \mathrm{MW}$ ), according to the recommendation of Zhou et al. (1997). $g$ is the acceleration of gravity, $g=9.81 \mathrm{~m} / \mathrm{s}^{2} . \bar{H}_{t}$ is the average reservoir water level during time step $t ; \overline{h_{t}}$ is the average tail water level during time step $t$. As mentioned in Eq. (5), $R_{t}^{e}$ is the

HESSD

3, 3771-3814, 2006

Effect of flow forecasting quality

on benefits of reservoir operation

X. Dong et al.

\section{Title Page}

Abstract Introduction

Conclusions

Tables

References

Figures

14

4

Back

Close

Full Screen / Esc

Printer-friendly Version

Interactive Discussion

EGU 
part of the release through the turbines during time step $t$. When the total release $R_{t}$ is smaller than $R^{e-\max }$, all released water will go through the turbines to generate electricity. When $R_{t}>R^{e-\max }$, the part exceeding $R^{e-\max }$ will go through the spillways.

In order to ensure a stable and reliable power supply (in addition to pursuing the 5 maximum benefit), the firm power is set to be $180 \mathrm{MW}$ under a design guarantee rate of $92 \%$ (see Sect. 2). To include this firm power requirement, Eq. (7) is modified by introducing a penalty function:

$B^{\max }=\max \left\{\sum_{t=1}^{T}\left[\eta g R_{t}^{e}\left(\overline{H_{t}}-\overline{h_{t}}\right)-v H_{t}^{e}\left|E^{f}-E_{t}\right|\right]\right\}$

where, $v H_{t}^{e}\left|E^{f}-E_{t}\right|$ is a penalty function added to the objective function to force the

10 algorithm to produce power greater than the firm power; $v$ is the penalty factor; $H_{t}^{e}$ is a unit step function:

$H_{t}^{e}= \begin{cases}0, & N_{t} \geq N^{f} \\ 1, & N_{t}<N^{f}\end{cases}$

$N_{t}$ is the power output at time step $t, \mathrm{~kW} ; N^{f}$ is the firm power $\left(N^{f}=180 \mathrm{MW}\right) ; E^{f}$ is the firm energy $\left(E^{f}=N^{f} \Delta t\right) ; \Delta t$ is the length of the time step.

15 The choice for the value of $v$ will remarkably influence the final annual electricity output and the design guarantee rate. In order to determine the appropriate value of $v$ that leads to the required design guarantee rate $(92 \%)$, an investigation on the relationship between the $v$ value and the guarantee rate was carried out. The results are shown in Table 1, which indicates that $v=0.4$ is the correct value for the penalty 20 factor.

4) Compute the water level transformation matrices for all time steps

The equation of storage volume transformation is formulated according to the water balance: the storage at the end of one time step is equal to the initial storage at the 3787
HESSD

3, 3771-3814, 2006

\section{Effect of flow} forecasting quality

on benefits of reservoir operation

X. Dong et al.

\section{Title Page}

Abstract Introduction

Conclusions

Tables

References

Figures

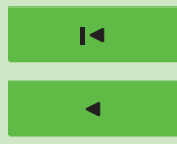

$>1$

Back

Close

Full Screen / Esc

Printer-friendly Version

Interactive Discussion

EGU 
beginning of the time step plus the incoming inflow volume during the time step and minus the total released volume during the time step. It is expressed by the following equation:

$S_{t+1}=S_{t}+\left(Q_{t}-R_{t}\right) \Delta t$

5 where $S_{t}$ is the reservoir storage $\left(\mathrm{m}^{3}\right)$ at the beginning of time step $t$. It is derived from the pool level and the storage - pool level relationship $\left(f^{S H}\right) . Q_{t}$ is the forecasted flow to the reservoir during time step $t\left(\mathrm{~m}^{3} / \mathrm{s}\right) . R_{t}$ is the total release from the reservoir during time step $t\left(\mathrm{~m}^{3} / \mathrm{s}\right) . \Delta t$ is the duration of the time step. The storage volume transformation is converted to the water level transformation using the storage - pool - level relationship.

The water level transformations at one time step are stored as a two-dimensional matrix. The combination of all these two-dimensional matrices (for all time steps) forms a three-dimensional transformation matrix, denoted as $\mathbf{P}$. The individual elements of the matrix are denoted as $P_{i, j, t}$, where, $i=1,2, \ldots, n ; j=1,2, \ldots, m ; t=1,2, \ldots, T$, 15 which means at time step $t$, starting with water level $H_{i}$, after the implementation of release $R_{j}$, the water level will reach the value saved in $P_{i, j, t}$. The constants $N, M$ and $T$ are the total number of water levels, releases and time steps respectively.

5) Compute the step benefit matrices for all time steps

The benefits obtained in individual time steps are calculated by the following equation:

$b_{t}=\eta g R_{t}^{e}\left[\overline{H_{t}}-\overline{h_{t}}\right]-v H_{t}^{e}\left|E^{f}-E_{t}\right|$

Similar to the water level transformation matrices, the benefits obtained at one time step are also stored as a two-dimensional matrix. The combination of all twodimensional benefit matrices (for all time steps) forms a three-dimensional benefit matrix, denoted as $\mathbf{b}$. The individual elements of the matrix are denoted as $b_{i, j, t}$, where, $i=1,2, \ldots, N ; j=1,2, \ldots, M ; t=1,2, \ldots, T$, which means at time

HESSD

3, 3771-3814, 2006

Effect of flow forecasting quality

on benefits of reservoir operation

X. Dong et al.

\section{Title Page}

Abstract Introduction

Conclusions

Tables

References

Figures

14

4

Back

Close

Full Screen / Esc

Printer-friendly Version

Interactive Discussion

EGU 
step $t$, starting with water level $H_{i}$, after the implementation of release $R_{j}$, the benefits obtained in this step are saved in $b_{i, j, t}$.

HESSD

6) Perform backward recursive optimization and determine optimal water level trajectory

5 The optimal solution of the objective function (Eq. 8) is a set of $T$ consecutive water levels (and correspondingly, releases), which form the optimal water level trajectory (and release strategy). A so-called backward recursive algorithm is used here to find the optimal water level trajectory (and release strategy). The equation of this algorithm can be written as:

$B_{t}^{*}=\max \left\{b_{t}+B_{t+1}^{*}\right\}, t=T, T-1, \ldots, 1$

$B_{T+1}=0$

where, $B_{t+1}^{*}$ are the benefits obtained from a set of optimal sub-strategies of releases from time step $t+1$ to the final time step $T ; b_{t}$ is the benefit obtained in time step $t$, calculated by Eq. (10).

Equation (11) reveals the soul of dynamic programming, which rests in the intuitive concept of Bellman's principle of optimality: "An optimal policy has the property that whatever the initial state and initial decision are, the remaining decisions must constitute an optimal policy with regard to the state resulting from the first decision" (Bellman, 1957). For the implementation in reservoir operation, this principle tells us that, an optimum water level trajectory (and release strategy) has the property that any portion of an optimal sub-trajectory (and sub-strategy) from an intermediate time step to the final time step is itself the optimal trajectory (and strategy) from that intermediate time step (Larson and Casti, 1978). This allows us to determine an overall optimum water level trajectory (and release strategy) and the corresponding optimum benefit by starting at the end of the time horizon and working backward one step at a time, considering only the water level at that time step. This process can be explained by following example.

\section{Effect of flow forecasting quality on benefits of reservoir operation}

X. Dong et al.

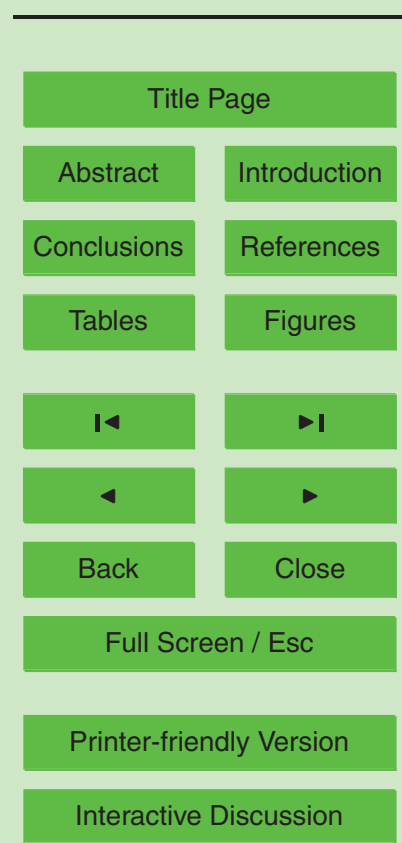


Figure 6 shows how to find the optimal water level trajectory (and release strategy) for a simple reservoir. The whole time horizon under consideration is divided into 4 time steps, the water level space is discretized into 3 water levels. A circle in the figure refers to a water level (state). The notation inside the circle, for example, $H_{2,3}$, refers to 5 water level 2 at the beginning of time step 3. The connections between the water levels are releases. For example, $R_{12,1}$, refers to the required release to have the water level rise from $\left(H_{1,1}\right)$ to $\left(H_{2,2}\right)$. The water level starts to rise from the dead water level $\left(H_{1,1}\right)$, and has to fall back again to the dead water level at the end of last time step $\left(H_{1,5}\right)$.

The backward recursive algorithm starts looking for the optimal releases from the end

of the time horizon. In time step 4, each water level has only one releasing strategy to the final water level. Therefore, they are all optimal water level sub-trajectories (denoted as $H_{1,4}^{*}, H_{2,4}^{*}$ and $\left.H_{3,4}^{*}\right)$ for the corresponding starting water levels $\left(H_{1,4}, H_{2,4}\right.$ and $\left.H_{3,4}\right)$. These optimal water level sub-trajectories are marked by thick lines. The corresponding optimal release sub-strategies are denoted as $R_{1,4}^{*}, R_{2,4}^{*}$ and $R_{3,4}^{*}$. Each results in a 15 sub-strategy benefit, denoted as $B_{1,4}^{*}, B_{2,4}^{*}$ and $B_{3,4}^{*}$.

Then the algorithm proceeds one step backwards to time step 3 , in which each water level has three feasible releases leading to the corresponding three water levels at the beginning of time step 4. For example, starting from $H_{3,3}$, there are three feasible releases: $R_{33,3}, R_{32,3}$ and $R_{31,3}$. Correspondingly, each water level at the beginning of time step 3 will have three step benefits (for example starting from $H_{3,3}$ the step benefits are $b_{33,3}, b_{32,3}$ and $\left.b_{31,3}\right)$. Next, for each water level at the beginning of time step 3 the optimal release strategy can be determined by calculating the benefits from time step 3 to the last time step and finding the maximum. For example, starting from $\mathrm{H}_{3,3}$ the three possible benefits are $b_{33,3}+b_{31,4}\left(B_{3,4}^{*}\right), b_{32,3}+b_{21,4}\left(B_{2,4}^{*}\right)$ and $b_{31,3}+b_{11,4}\left(B_{1,4}^{*}\right)$. Assume that in this example $b_{33,3}+b_{31,4}>b_{32,3}+b_{21,4}>b_{31,3}+b_{11,4}$, then $H_{3,3}-H_{3,4}-H_{1,5}$ is the optimal water level sub-trajectory, starting from water level $H_{3,3}$. The other 2 feasible water level sub-trajectories $\left(H_{3,3}-H_{2,4}-H_{1,5}\right.$ and $\left.H_{3,3}-H_{1,4}-H_{1,5}\right)$ are abandoned for further optimization, because if the final optimal water level trajectory goes through $H_{3,3}$, then $H_{3,3}-H_{3,4}-H_{1,5}$ will automatically be the optimal trajectory to the end of the
HESSD

3, 3771-3814, 2006

\section{Effect of flow \\ forecasting quality \\ on benefits of \\ reservoir operation}

X. Dong et al.

\section{Title Page}

Abstract

Introduction

Conclusions

Tables

References

Figures

14

4

Back

Full Screen / Esc

Printer-friendly Version

Interactive Discussion 
time horizon (see the "Bellman's principle of optimality" in previous paragraphs). The same can be done for the other two water levels at time step 3, leading to three optimal release sub-strategies from time step 3 (because there are three beginning water levels in time step 3). They are again marked by thick lines. Therefore, although there 5 are in total nine feasible sub-trajectories from time step 3 to the end, the algorithm only needs to memorize three optimal water level sub-trajectories for further optimization. By this way, the algorithm saves memory and it is quicker to find the optimum.

The same operation applies one step backward to time step 2, and three optimal water level sub-trajectories are found again in correspondence to the three feasible 10 water levels at the beginning of time step 2. Again only these three optimal water level sub-trajectories are memorized for the optimization in the time step 1.

There is only one feasible water level (the dead water level) at the beginning of time step 1. After calculating the three step benefits, $H_{1,1}-H_{2,2}-H_{1,3}-H_{1,4}-H_{1,5}$ is found to be the optimal water level sub-trajectory starting from the first time step.

\section{7) Extract optimal release strategy and calculate maximum benefit}

Following the optimal water level trajectory $H_{t}^{*}(t=1,2, \ldots, T)$, the optimal release strategy $R_{t}^{*}(t=1,2, \ldots, T)$ can be extracted forwardly from the first to the last time step (in the example of Fig. 6 this is: $\left.R_{12,1}-R_{21,2}-R_{11,3}-R_{11,4}\right)$. The step benefits $b_{t}^{*}(t=1,2, \ldots, T)$, corresponding to the optimal water level trajectory and optimal release strategy can then be extracted from the step benefit matrix. The maximum overall benefit is then calculated as the summation of these step benefits: $b_{t}^{*}(t=1,2, \ldots, T): B^{\max }=\sum_{t=1}^{T} b_{t}^{*}$.
HESSD

3, 3771-3814, 2006

\section{Effect of flow forecasting quality \\ on benefits of reservoir operation}

X. Dong et al.

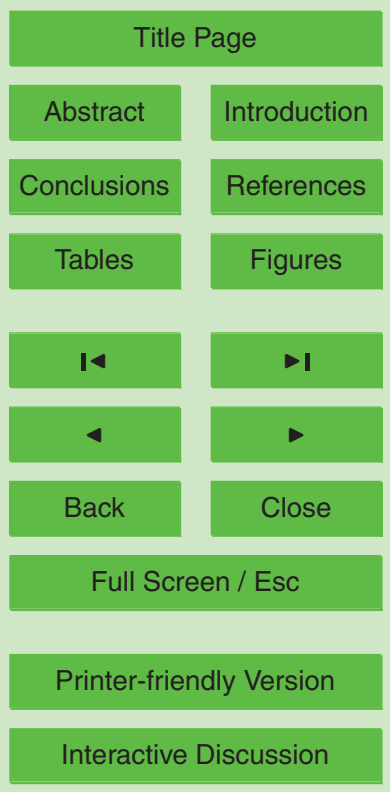




\section{Results}

\subsection{Actual and theoretical maximum benefits}

A reference benefit needs to be set, against which comparisons among the benefits obtained under varying qualities of flow forecasting can be made. Normally, the actual 5 benefit (in terms of electricity generated) is used as the reference benefit. For the Geheyan reservoir, the actual electricity generated during the hydrological year 1997 is $2.2 \times 10^{9} \mathrm{kWh}$, according to the reports provided by the Reservoir Regulation Centre of the Qingjiang Hydropower Development Cooperation (QHDC and CWRC, 1998).

The problem of using the actual benefit as a reference is it is subjected to the actual operation strategies. Once different operation strategies are used, the actual benefit will change accordingly. Therefore, it is not a stable, objective reference. For this reason, we use the so-called "theoretical maximum benefit" as a reference. The theoretical maximum benefit is the benefit obtained for the reservoir being optimized with inflows forecasted perfectly along the complete time horizon considered. For the Geheyan reservoir, in order to calculate this theoretical maximum benefit, the observed flow into the reservoir is used as the perfect forecasting. Since the considered time horizon is the hydrological year 1997, the lead time of the forecast is one year.

Part of Fig. 7 shows the optimization results obtained with a lead time of one year and perfect inflow forecast. Figure $7 \mathrm{a}$ is the observed inflow for the hydrological year 1997, which served as the inflow forecast. The thick solid lines in Figs. 7b, c and d are the optimization results for respectively the optimal release strategy, water level trajectory and the electricity generated. According to Fig. 7d, the theoretical maximum benefit is $3.0 \times 10^{9} \mathrm{kWh}$. It will be used as the reference benefit to make comparisons.

\subsection{Effects of forecasting lead time on benefits}

In addition to the theoretical maximum benefit, the benefits obtained from a perfect flow forecast with a lead time of 4 and 10 days are studied, to determine the effect of
HESSD

3, 3771-3814, 2006

\section{Effect of flow forecasting quality on benefits of reservoir operation}

X. Dong et al.

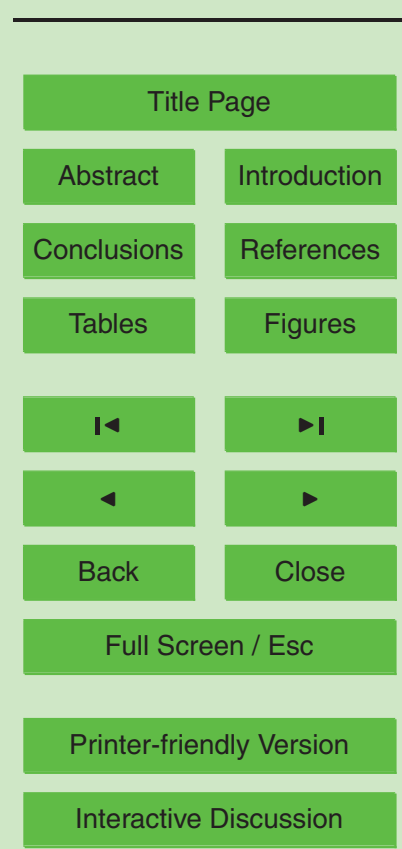

EGU 
the lead time of flow forecasting on the benefit. The results are presented in Fig. 7 as well. The optimal results for lead times of 4 and 10 days with perfect flow forecasts are illustrated in Figs. 7b, c and d as thin solid and dashed lines, respectively.

Figure $7 \mathrm{a}$ is the observed inflow series for the hydrological year 1997. There were

5 two successive peaks during this flooding event; the second started 2 days after the first.

Figure $7 \mathrm{~b}$ presents the optimized releases from the reservoir. Releases less than $1300 \mathrm{~m}^{3} / \mathrm{s}$ (the maximum release via turbines) are released through the turbines to generate electricity. For releases higher than that, the surpluses are released through 10 flood-releasing works (spill gates, spillways or bypass conduits). The total wasted volume can be calculated by integrating the releases through the flood-releasing works over time. The total wasted volumes for perfect flow forecasts with a lead time of 1 year, 10 and 4 days are $0.8 \times 10^{9}, 2.0 \times 10^{9}$ and $2.5 \times 10^{9} \mathrm{~m}^{3}$ respectively, corresponding to 6 , 16 and $20 \%$ of the average annual flow volume $\left(12.65 \times 10^{9} \mathrm{~m}^{3}\right.$, see Sect. 2$)$. Therefore, 15 for increasing lead times, the volume of water that will be spilled decreases. Before the arrival of the flood of July 1997, flow forecasts with longer lead times resulted in earlier full-load operation of the generators, in order to generate more electricity by decreasing the volume of the spilled water.

This pre-releasing (before the arrival of the flood) can also be identified easily from

20 Fig. 7c: for flow forecasts with longer lead times, the water level starts to decrease earlier, relative to the arrival of the flood event as a result of optimization. Another issue revealed by Fig. 7c is that although the flood event in July 1997 lasted for only 10 days, the reservoir needed to start depleting the storage about 30 days before the beginning of the flood in order to generate maximum electricity. However, if the major operational purpose of the reservoir were not power generation, but for instance flood defence, pre-releasing would be able to start much later because the releasing capacity of the flood sluices is much bigger than that of the turbines.

Figure $7 d$ shows the optimized power output in the hydrological year 1997. Table 2 lists the corresponding total benefits (in terms of electricity generated) as well as the

HESSD

3, 3771-3814, 2006

\section{Effect of flow \\ forecasting quality \\ on benefits of \\ reservoir operation}

X. Dong et al.

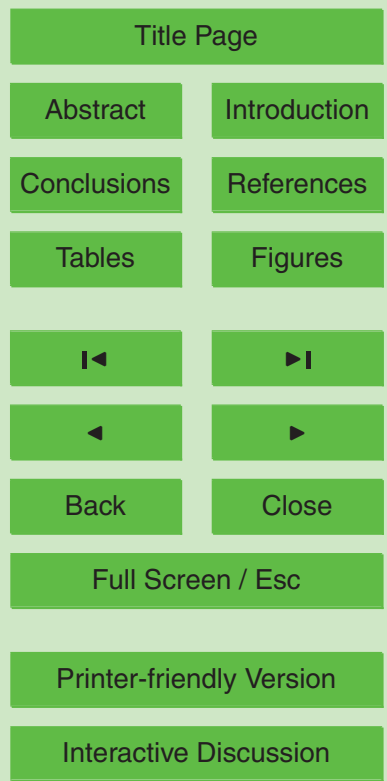

EGU 
benefit obtained from the actual operation. As shown in Table 2, the theoretical maximum benefit $\left(3.0 \times 10^{9} \mathrm{kWh}\right)$ is much higher $(27 \%)$ than the actually obtained benefit $\left(2.2 \times 10^{9} \mathrm{kWh}\right)$. Perfect flow forecasts with a lead time of 10 days and 4 days can realize $93 \%$ and $87 \%$ of the maximum benefit respectively.

5 According to Fig. 7c, because of the flood event in July, the reservoir started to prerelease the storage prior to the arrival of the flood. In order to identify precisely when pre-releasing the storage has to start, the optimization results before, during and after the flood event are sampled from Fig. 7, enlarged and displayed in Fig. 8. The sampling duration is from 11 June to 26 July 1997.

10 According to Fig. 8c, in order to maximize the benefits, the reservoir operation related to the flood event consists of two successive stages: pre-releasing and refilling. The refilling always starts (or the pre-releasing always ends) at the beginning of the flood event: 14 July, to make maximum use of the flooding water. From that time, the refilling will continue until the maximum water level is reached. The duration of the refilling 15 depends on the volume emptied by the pre-releasing operation. Notice that, for flow forecasts with a lead time equal to 4 and 10 days, the refilling durations (from 14 July to 16 July) are 2 days shorter than when the lead time of the flow forecast is 1 year (which the refilling is from 14 July to 18 July ). The duration of the pre-releasing increases for increasing lead times of flow forecasts: 2 and 8 days for forecast lead times of 4 and 10 days respectively. For flow forecasting with a lead time of 4 and 10 days, the total duration of the pre-releasing and refilling periods $\left(T^{d}\right)$ is equal to the lead time.

For lead times smaller than 33 days, $T^{d}$ increases with the increase of $T^{\prime}$, and $T^{d}=T^{\prime}$. However, Fig. $8 \mathrm{c}$ shows that it will not always increase with the increase of lead time $T^{\prime}$. For $T^{\prime}$ equal to 1 year, $T^{d}$ is 33 days (the water level starts to decrease on 15 June, 25 and fills up again on 18 July). It is anticipated that for $T^{\prime}$ greater than 33 days, $T^{d}$ will not be more than 33 days, because the dead water level has already been reached: no more space can be made available under forecasts with longer lead times. Therefore, 33 days is identified as the maximum $T^{d}$. Also, it is the maximum required lead time of the flow forecast $\left(T^{\prime}\right)$ in order to reach the theoretical maximum benefit. Therefore, it

HESSD

3, 3771-3814, 2006

\section{Effect of flow forecasting quality on benefits of reservoir operation}

X. Dong et al.

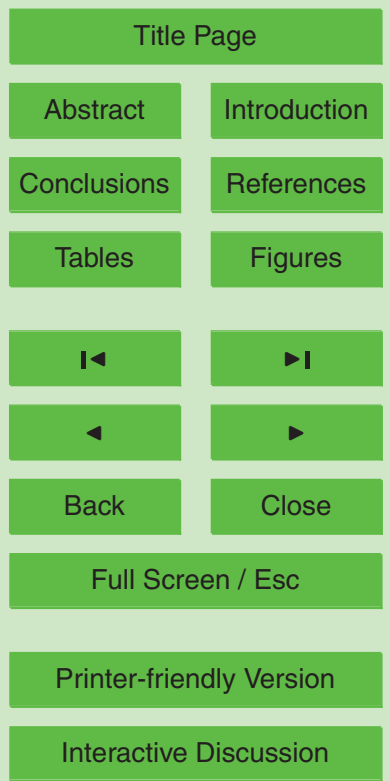


is denoted as the threshold lead time $\left(T^{\text {-threshold }}\right)$. Further extension of the forecasting lead time beyond $T^{l \text {-threshold }}$ will not lead to a significant increase in benefit. Although a lead time of 33 days is not realistic, the $T^{l \text {-threshold }}$ gives the upper limit of an appropriate flow forecasting in terms of lead time. The value of the threshold lead time depends 5 on:

1. the physical features of the reservoir, such as the storage volume and the releasing capacity of the turbines and the flood-releasing works; and

2. the character of the impending flooding events: larger flooding events (either larger volumes or higher peak discharges) will lead to longer threshold lead times.

10 As a lead time of 33 days is infeasible in reality, the feasible lead time of a flow forecasting can be determined by considering the hydrological response time of the basin and the lead time of rainfall forecasts. In order to investigate the influence of the forecasting accuracies on the benefits, a feasible lead time of 4 days (a hydrological response time of 1 day and a lead time of rainfall forecasts of 3 days) will be chosen to estimate the effects of forecasting accuracies on the benefits.

\subsection{Effects of forecasting accuracy on benefits}

Figures 9 and 10 present the optimized benefits calculated from the generated flow series with different forecasting accuracies. In these two figures, the trends of the relations between benefits and accuracy are indicated by adding curves fitted to the data pairs. A linear equation is used for both figures. As can be seen from these two figures, the benefits increase generally with increasing model performances (either in $R_{N S}$ or in RMAE terms). In order to prove that there exists an increasing (or decreasing) trend in the data presented in Figs. 9 and 10, a mean line (the dashed lines), which represents the mean value of the benefits, is added to both figures. The Mean Squared Errors (MSE) of both fitted lines (solid lines) and mean lines (dashed lines) with respect to the data (the dots) are calculated to show their goodness-of-fit to the data. The MSE
HESSD

3, 3771-3814, 2006

Effect of flow forecasting quality on benefits of reservoir operation

X. Dong et al.

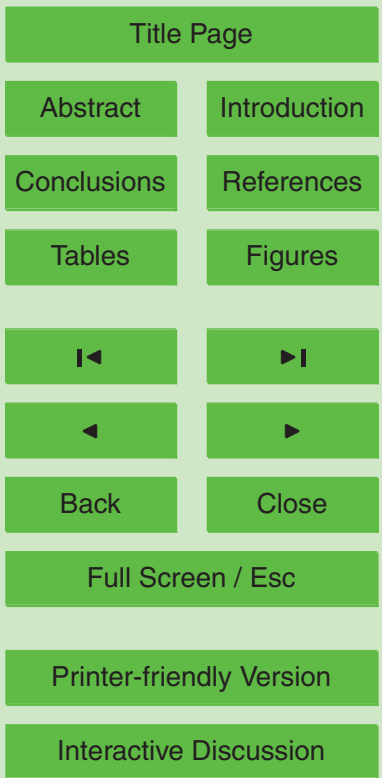

EGU 
values are shown in both figures. As can be seen, the MSE values for the fitted lines in both figures are smaller than the MSE values for the mean lines. This means that the solid lines fit the data better than the dashed lines. This proves that the increasing or decreasing trends discovered in Figs. 9 and 10 by the fitted curves are correct. This 5 trend analysis assumes that, if the MSE of the fitted line is smaller than the MSE of the mean line, there is always a trend. Further research on testing the truth of this hypothesis may be necessary. It can be intuitively known that, the truth of this hypothesis relates to the number of data pairs, and the significance level pre-determined for this hypothesis test.

The actual total electricity generated from the real operation is $2.2 \times 10^{9} \mathrm{kWh}$. According to the fitted curves in Figs. 9 and 10, any 4-day ahead flow forecasting with a $R_{N S}$ greater than 0.70 (or RMAE less than 0.40 ) can at least yield an electricity of $2.31 \times 10^{9} \mathrm{kWh}$, an increase of $5 \%$ compared to the actual operation. If we assume an $R_{N S}$ value of 0.90 (or an RMAE value of 0.25 ) to be feasible for a 4-day ahead 15 flow forecasting, then electricity of $2.40 \times 10^{9} \mathrm{kWh}$ can be obtained, an increase of $9 \%$ compared to the actual operation. Thus, benefit increases varying from $5 \%$ to $9 \%$ are typical with respect to the real operation results.

An appropriately accurate flow forecast can be defined as a forecast that leads to a certain benefit, expressed as a percentage of the theoretical maximum benefit. For ex20 ample, if a benefit of $80 \%$ of the theoretical maximum benefit (which is $2.40 \times 10^{9} \mathrm{kWh}$ ) is required, a flow forecasting with accuracy in terms of an $R_{N S}$ value of 0.88 is necessary. The choice for the criterion depends not only on the reservoir operator's preference, but also on the physical reality of the studied river basin. In general, a basin with a larger area, a longer river channel and more stable climate conditions generally 25 leads to more reliable flow forecasting and may result in benefit closer to the theoretical maximum benefits.
HESSD

3, 3771-3814, 2006

\section{Effect of flow forecasting quality on benefits of reservoir operation}

X. Dong et al.

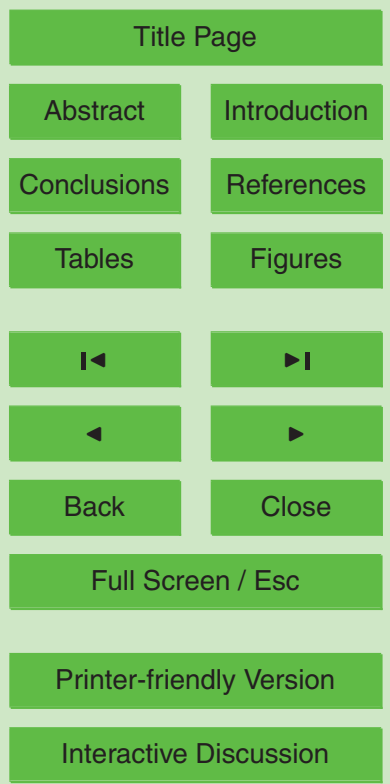

EGU 


\section{Discussion}

Figures 9 and 10 indicate that high-accuracy flow forecasts do not always lead to large benefits. The relationships between benefit and forecasting accuracies are quite dispersed. This scatter of the data points may be explained by the following three reasons:

1. A sub-optimal release (because of mis-estimation of the flow) made at a certain stage will yield losses in the future. For example, an overestimation of the flow at the end of a flood season will lead to the release of water to lower the water level. Because of a lack of flow water during the following dry season, the water level will remain low for a long period, during which the power output will be lower than that when a correct estimation of the flow is made. This effect will be smaller in the flooding season, because the extra released volume can be easily refilled by abundant flooding water in the flooding season. Because of the randomness in generating the forecasting errors for the generated flow series, the chance of over-depletion of the storage and the long-term consequences of benefit losses are also random. Therefore, even if the overall $R_{N S}$ values of flow forecasts are satisfactory, the variation in the benefits is very high.

2. Both $R_{N S}$ and RMAE are criteria designed for measuring the difference between the forecasted and observed flow series (forecasting errors), not for measuring an increase in electricity obtained from better flow forecasting. As seen from Eq. (8), the forecasting errors do not play an explicit role in determining the amount of electricity generated. Their influence on the benefits will have to be taken into consideration through reservoir operation practices and will either depress or enhance the benefits to some degree (a random process, as explained). A new, more effective measure of flow forecasting accuracy for improving power generation may be more appropriate to identify this benefit - accuracy relationship.

3. Flow forecasting is not the only factor which has a fundamental influence on the improvement of power generation; the operation strategies also play an important 3797
HESSD

3, 3771-3814, 2006

Effect of flow forecasting quality on benefits of reservoir operation

X. Dong et al.

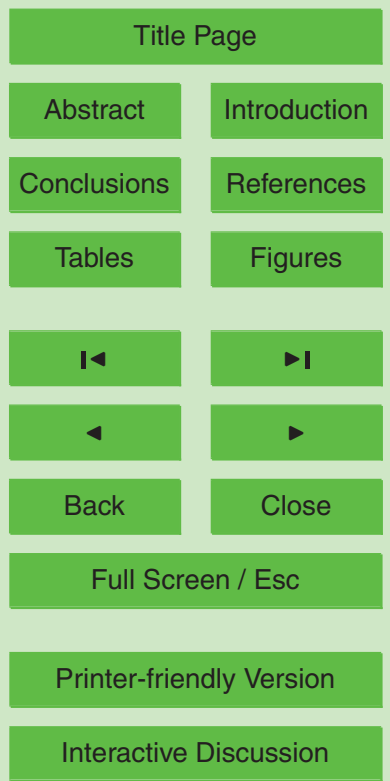

EGU 
role. The question which one (forecasting or operation) dominates remains a question to be answered.

HESSD

Figures 9 and 10 show the benefit - accuracy relation for one single lead time (4 days). If enough simulations for multiple lead times are performed, a 3-dimensional 5 benefit - lead time - accuracy relationship can be obtained, as shown in Fig. 11.

In Fig. 11, the benefit - lead time plane presents the benefits obtained under perfect flow forecasts (RMAE $=0$ ). It is expected that the benefit increases in a hyperbolic way with respect to the increase of the lead time of the flow forecast. Such an expectation is made under an anticipation that, the increase in benefits will be insignificant when the 10 lead time is larger than 33 days - the threshold lead time. The reason has been given in Sect. 6.2. According to this benefit - lead time plane, the benefit will not increase unlimitedly. One theoretical maximum benefit is indicated on this plane: the benefit obtained under a perfect flow forecasting with a lead time of 1 year ( 365 days). If perfect flow forecasting with a lead time longer than one year is available, this theoretical maximum benefit can be higher, but this will not be considered in this research, because (1) the studied reservoir - the Geheyan Reservoir is designed for a year-round operation; (2) care has to be paid to use the flow forecast with a lead time more than one year, because of the significant uncertainties in it. For a given lead time, the benefits obtained from flow forecasts will decrease in general with increased level of forecasting error. For the forecast error - lead time relationship revealed on the forecast error lead time plane, it is expected that, the extension of the lead time will generally result in an increase of forecasting error. Because it is not known how this increase occurs, a linear relation is drawn.

\section{Conclusions}

This research aims at developing a methodology to carry out a benefit analysis of reservoir operation, based on which the required lead time and accuracy of flow forecasting
3, 3771-3814, 2006

\section{Effect of flow forecasting quality \\ on benefits of reservoir operation}

X. Dong et al.

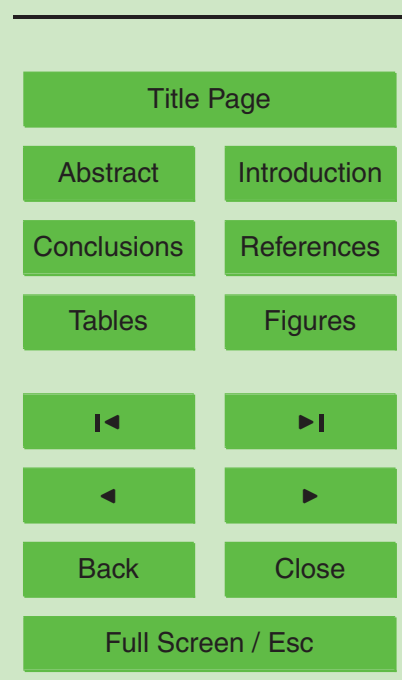

Printer-friendly Version

Interactive Discussion 
for reservoir operation can be identified.

In order to evaluate the benefits completely, a method to couple the long-term and short-term optimization sub-models was developed. The key of this coupling method is to use the long-term optimization results to guide the short-term optimization proce5 dures, i.e., the terminal water levels of the short-term optimization procedures are taken from the long-term optimization results. This coupling method proves to be effective as revealed in the results.

The benefits obtained from the actual operation turn out to be $73 \%$ of the theoretical maximum benefits. A perfect flow forecasting with a lead time of 4 days will result in $1087 \%$ of the theoretical maximum benefit in one year. A further increase of the lead time will increase the benefit. This increase will be insignificant for lead times greater than 33 days (the threshold lead time) for this specific reservoir and hydrological year.

The derived threshold lead time (33 days) is not feasible with the present flow forecasting techniques. Therefore, the definition of the appropriate lead time will depend solely on the physical conditions of the basin and on the characteristics of the reservoir. For flow forecasting with a fixed, feasible lead time of 4 days and different forecasting accuracies, the benefits can increase from 5 to $9 \%$ compared to the actual operation results.

Criteria for the appropriate forecasting accuracy for a specific feasible lead time should be defined from the benefit - accuracy relationship, starting with setting a preferred benefit level, in terms of percentage of the theoretical maximum. However, it has to be kept in mind that higher accuracy flow forecasting does not always increase the benefit. The obtained benefit also depends on the operation strategies of the reservoir. The effect of the interaction between the flow forecasting and the reservoir operation strategies on the benefit needs to be further explored.

Acknowledgements. This work is supported by the Royal Netherlands Academy of Arts and Sciences (KNAW) under contract number 02CDP006. The hydrological data are kindly provided by the Qingjiang Hydropower Development Corporation (QHDC), China.

HESSD

3, 3771-3814, 2006

\section{Effect of flow forecasting quality on benefits of reservoir operation}

X. Dong et al.

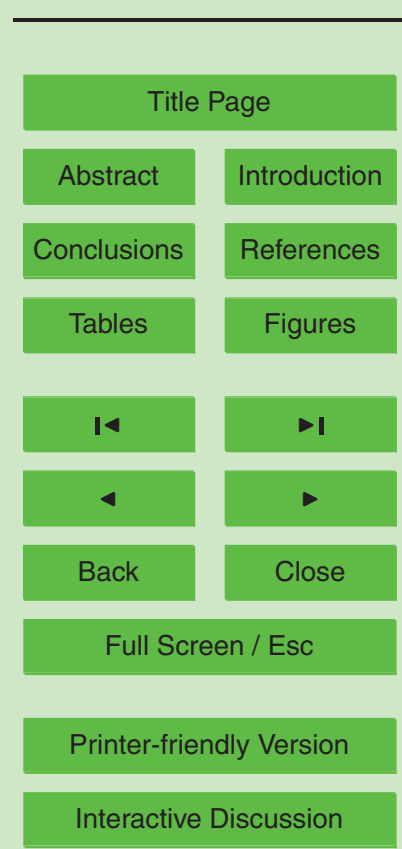




\section{References}

Becker, L., Yeh, W. W.-G., Fults, D., and Sparks, D.: Operations models for central valley project, J. Water Res. Plan. Manage. Div., 102(WR1), 101-115, 1976.

Bellman, B.: Dynamic programming. Princeton University Press, Princeton, New Jersey, USA, 1957.

Burgers, S. J. and Hoshi, K.: Incorporation of forecasted seasonal runoff volumes into reservoir management. Water Resources Series Technical Report No. 58, Department of Civil and Environmental Engineering, University of Washington, Seattle, Washington, USA, 1978.

De Kok, J. L., Van der Wal, K., and Booij, M. J.: Appropriate accuracy of models for decision support systems: Case example for the Elbe River basin, in: Complexity and Integrated Resources Management, edited by: Pahl-Wostl, C., Schmidt, S., Rizzoli, A. E., and Jakeman, A. J., Transactions of the 2nd Biennial Meeting of the International Environmental Modelling and Software Society, 2, 1021-1026, 2004.

Dong, X.: Appropriate flow forecasting for reservoir operation, PrintPartners Ipskamp BV, Enschede, the Netherlands, 2005.

Dong, X., Dohmen-Janssen, C. M., and Booij, M. J.: Appropriate spatial sampling of rainfall for flow simulation, Hydro. Sci. J., 50(2), 279-298, 2005.

Georgakakos, A. P. and Marks, D. H.: A new method for the real-time operation of reservoir systems, Water Resour. Res., 23(7), 1376-1390, 1987.

20 Georgakakos, A. P.: The value of streamflow forecasting in reservoir operation, Water Resour. Bull., 25(4) 789-800, 1989.

Hamlet, A. F. and Lettenmaier, D. P.: Columbia river streamflow forecasting based on ENSO and PDO climate signals, J. Water Resour. Plan. Manage., 125(6), 333-341, 1999.

Hamlet, A. F., Huppert, D., and Lettenmaier, D. P.: Economic value of long-lead streamflow forecasts for Columbia river hydropower, J. Water Resour. Plan. Manage., 128(2), 91-101, 2002.

Karamouz, M., Szidarovszky, F., and Zahraie, B.: Water Resources Systems Analysis. Lewis Publishers, USA, 2003.

Larson, R. E. and Casti, J. L.: Principles of Dynamic Programming, Part 1: Basic Analytic and Computational Methods, Marcel Dekker Inc., New York and Basel, 1978.

Legates, D. R. and McCabe Jr., G. J.: Evaluating the use of "goodness-of-fit" measures in hydrologic and hydroclimatic model validation, Water Resour. Res., 35(1), 233-241, 1999.

\section{HESSD}

3, 3771-3814, 2006

\section{Effect of flow \\ forecasting quality \\ on benefits of \\ reservoir operation}

X. Dong et al.

\section{Title Page}

Abstract

Introduction

Conclusions

Tables

References

Figures

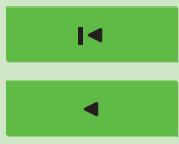

- I

Back

Close

Full Screen / Esc

Printer-friendly Version

Interactive Discussion 
Linsley, R. K., Franzini, J. B., Freyberg, D. L., and Tchobanoglous, G.: Water-resources Engineering, McGraw-Hill Inc., New York, USA, 1992.

Maidment, D. R.: Handbook of Hydrology, McGraw-Hill Inc., New York, USA, 1992.

Ministry of Water Resources of People Republic of China: Standard for essential technical terms and symbols in hydrology, China Planning Press, Beijing, China, 1999 (in Chinese).

Nash, J. E. and Sutcliffe, J. V.: River flow forecasting through conceptual models, Part 1-A discussion of principles, J. Hydrol., 10, 282-290, 1970.

QHDC (Qingjiang Hydropower Development Corporation-Reservoir Regulation Center) and CWRC (Changjiang Water Resources Committee-Department of Planning): Regulation rules of Geheyan reservoir-Qingjiang, Hubei, China, (eds.), 1998 (in Chinese).

ReVelle, C., Joeres, E., and Kirby, W.: The linear decision rule in reservoir management and design: 1. Development of the stochastic model, Water Resour. Res., 5(4), 767-777, 1969.

Yeh, W. W.-G., Sohn, R. L., and Becker, L.: Information requirements for improving hydropower, J. Water Res. Plan. Manage., 104(1), 139-156, 1978.

Yeh, W. W. G., Becker, L., Cohn, M. J., and Zettlemoyer, R.: Benefits of long-range streamflow prediction, Contribution No. 181, California Water Resources Center, University of California, Davis, CA, USA, 1980.

Yeh, W. W.-G., Becker, L., and Zettlemoyer, R.: Worth of flow forecast for reservoir operation, J. Water Res. Plan. Manage., 108, 257-269, 1982.

Zhou, Z., Shen, Z., Shi, X., and Li, T.: Water Resources and Hydropower Planning, second edition, China Water Power Press, Beijing, China, 1997 (in Chinese).

\section{HESSD}

3, 3771-3814, 2006

\section{Effect of flow forecasting quality \\ on benefits of reservoir operation}

X. Dong et al.

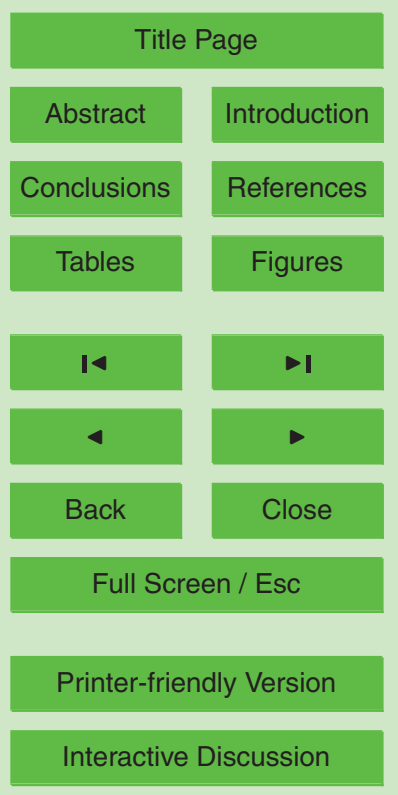




\section{HESSD}

3, 3771-3814, 2006

\section{Effect of flow forecasting quality on benefits of reservoir operation}

X. Dong et al.

Table 1. The influence of the penalty factor $(v)$ on the resulting guarantee rate.

\begin{tabular}{lllllllllll}
\hline$v$ & 0.1 & 0.2 & 0.3 & 0.4 & 0.5 & 0.6 & 0.7 & 0.8 & 0.9 & 1 \\
\hline guarantee rate (\%) & 83 & 86 & 89 & 92 & 95 & 95 & 95 & 96 & 96 & 96 \\
\hline
\end{tabular}

Title Page

Abstract

Introduction

Conclusions

References

Tables

Figures

14

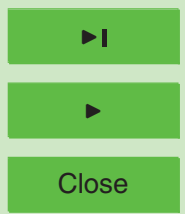

Back

Full Screen / Esc

Printer-friendly Version

Interactive Discussion 


\section{HESSD}

3, 3771-3814, 2006

\section{Effect of flow forecasting quality on benefits of reservoir operation}

X. Dong et al.

Table 2. Expected benefits under perfect flow forecasting and actual benefit obtained from real operation.

\begin{tabular}{llll}
\hline & Lead time (days) & Benefits $\left(\times 10^{9} \mathrm{kWh}\right)$ & $\%$ of benchmark benefit \\
\hline \multirow{3}{*}{ Perfect flow forecasts } & 365 & 3.0 & 100 \\
Actual operation & 10 & 2.8 & 93 \\
& 4 & 2.6 & 87 \\
\end{tabular}
Introduction
Title Page

Abstract

Conclusions

References

Tables

Figures

14

4

Back

Close

Full Screen / Esc

Printer-friendly Version

Interactive Discussion 


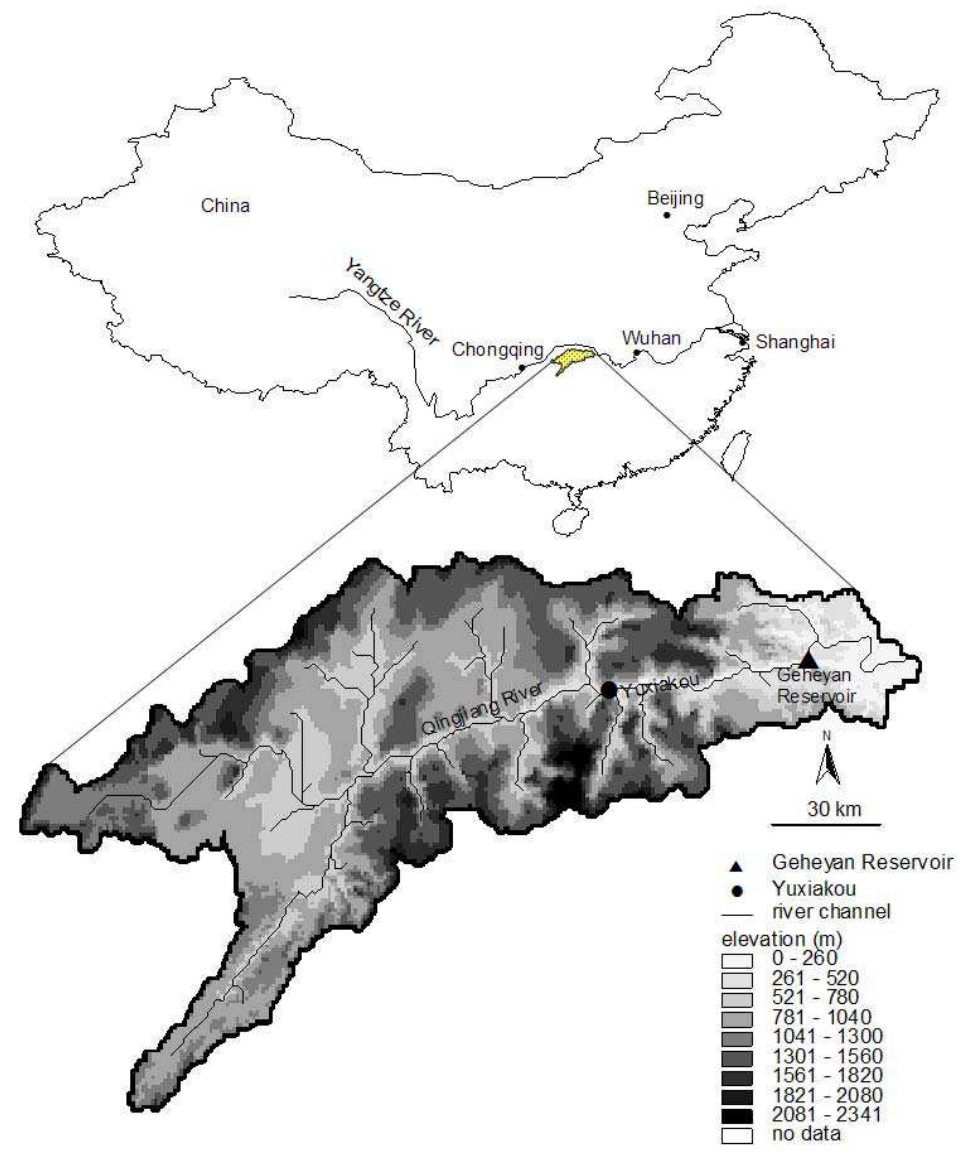

Fig. 1. The geographic location of Qingjiang River basin and the Geheyan Reservoir (the tail of the reservoir reaches Yuxiakou).

\section{HESSD}

3, 3771-3814, 2006

\section{Effect of flow forecasting quality on benefits of reservoir operation}

X. Dong et al.

Title Page
Abstract

Conclusions

Tables

14

4

Back
Introduction

References

Figures

$\rightarrow$

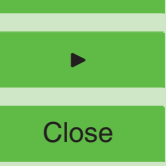

Full Screen / Esc

Printer-friendly Version
Interactive Discussion 


\section{HESSD}

3, 3771-3814, 2006

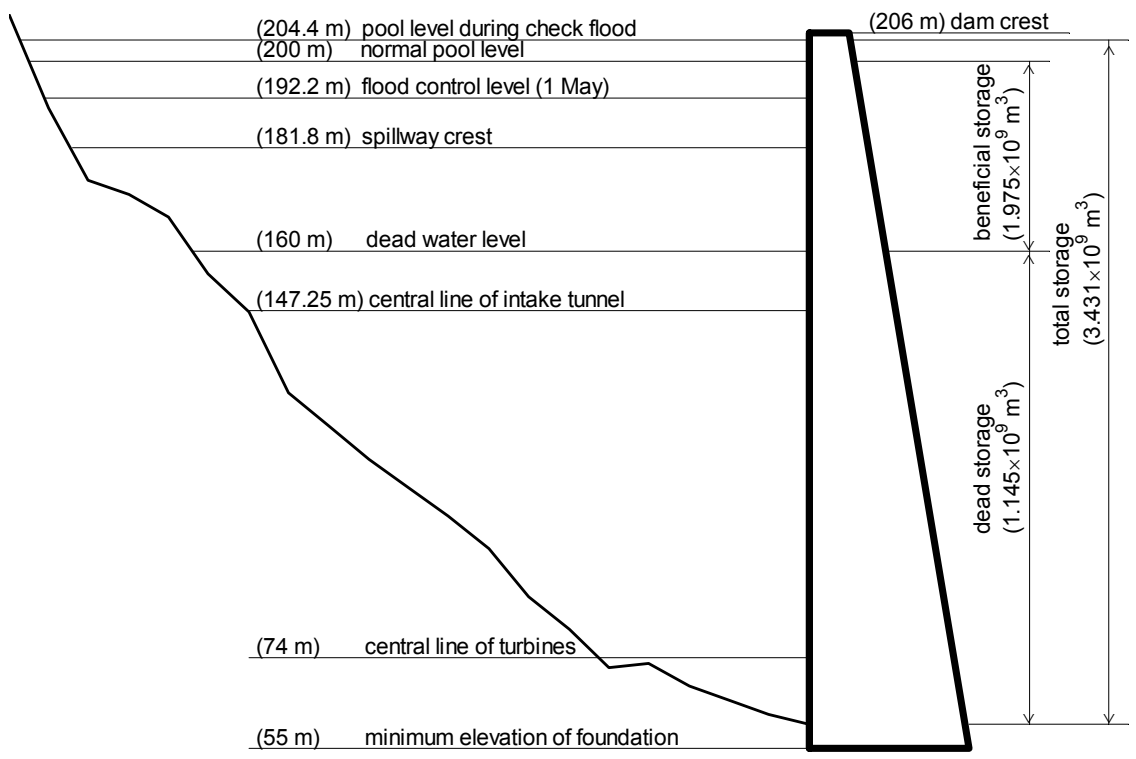

\section{Effect of flow forecasting quality \\ on benefits of reservoir operation}

X. Dong et al.

\section{Title Page}

\section{Abstract}

Conclusions

Tables

14

4

Back
Introduction

References

Figures

$\rightarrow$

Close pool level is the maximum elevation to which the reservoir surface will rise during ordinary operation conditions (Linsley et al., 1992). The dead-water level is the minimum endurable water level of the reservoir under normal hydrological and operational conditions. The difference in storage volume between the normal pool level and dead water level is defined as the beneficial storage.

\section{Full Screen / Esc}

Printer-friendly Version

Interactive Discussion 


\section{HESSD}

3, 3771-3814, 2006

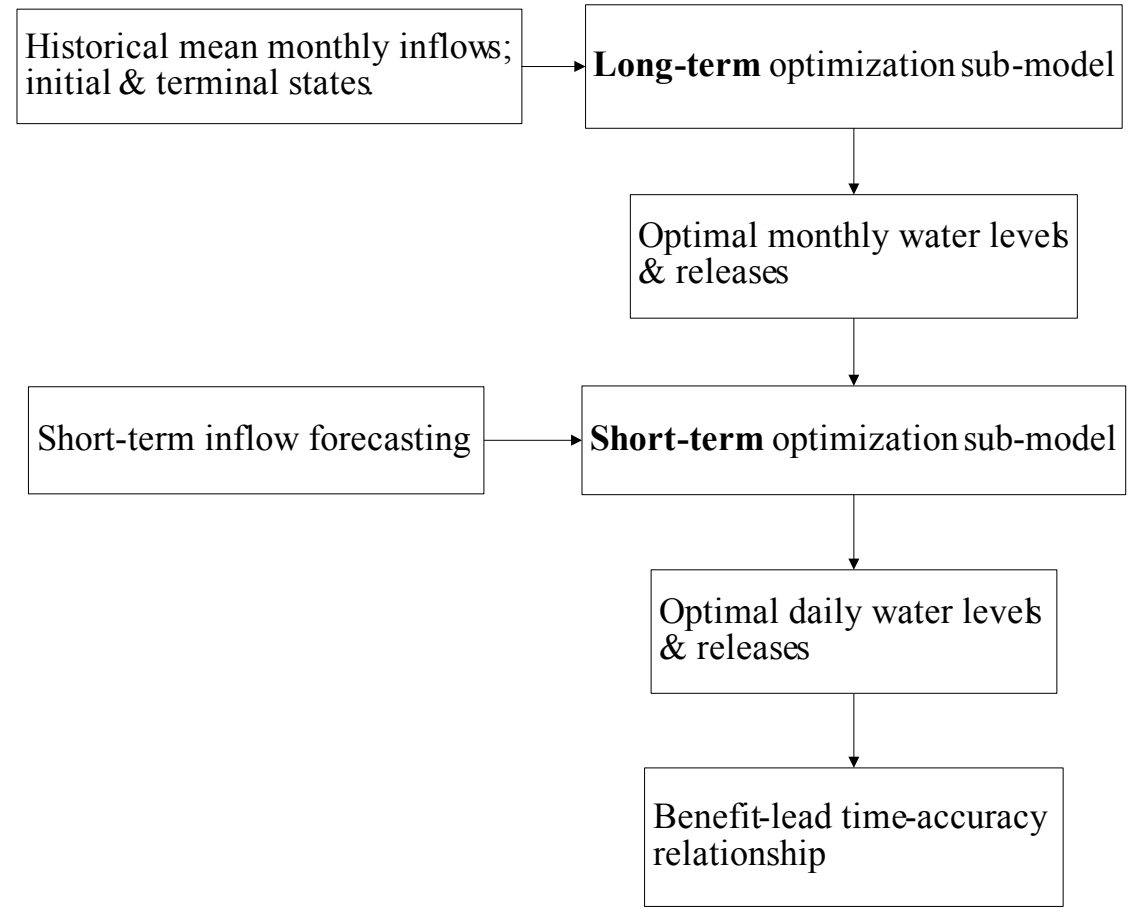

Effect of flow forecasting quality on benefits of reservoir operation

X. Dong et al.

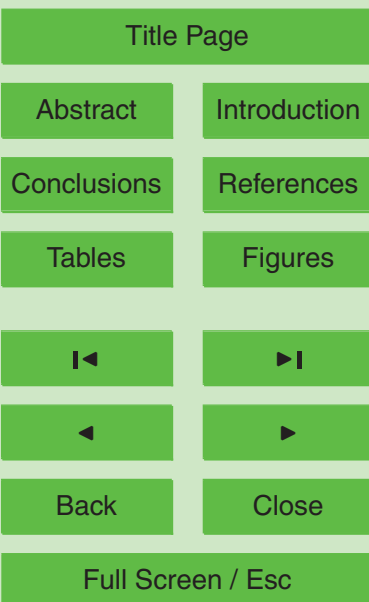

Fig. 3. Hierarchical structure of long-term and short-term optimization of reservoir operation.

Printer-friendly Version

Interactive Discussion 


\section{HESSD}

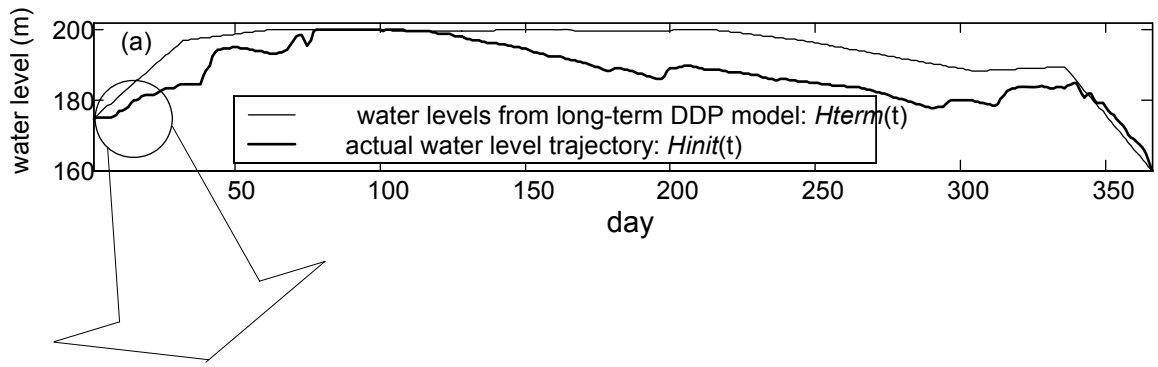

\section{3, 3771-3814, 2006}

\section{Effect of flow forecasting quality \\ on benefits of reservoir operation}

X. Dong et al.

(b) coupling of short- and long-term optimization model

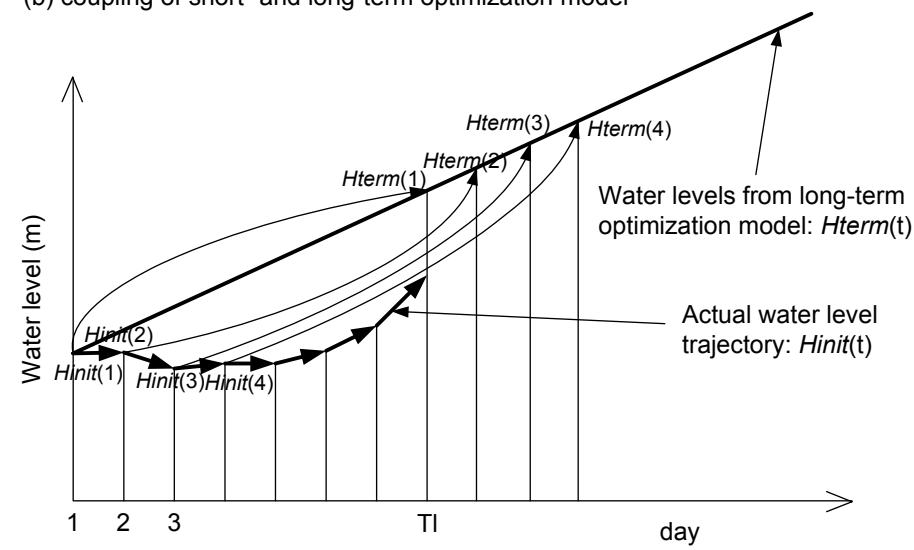

Title Page

Abstract

Introduction

Conclusions

References

Tables

Figures

14

$\rightarrow$ I

4

Back

Close

Full Screen / Esc

Fig. 4. Coupling of the long-term and short-term optimization models. Hinit(t) are actual water levels which serve as the initial conditions of every short-term optimization cycle; Hterm(t) are long-term optimization results, interpolated into daily water levels, serving as terminal conditions for each short-term optimization cycle.

Interactive Discussion 


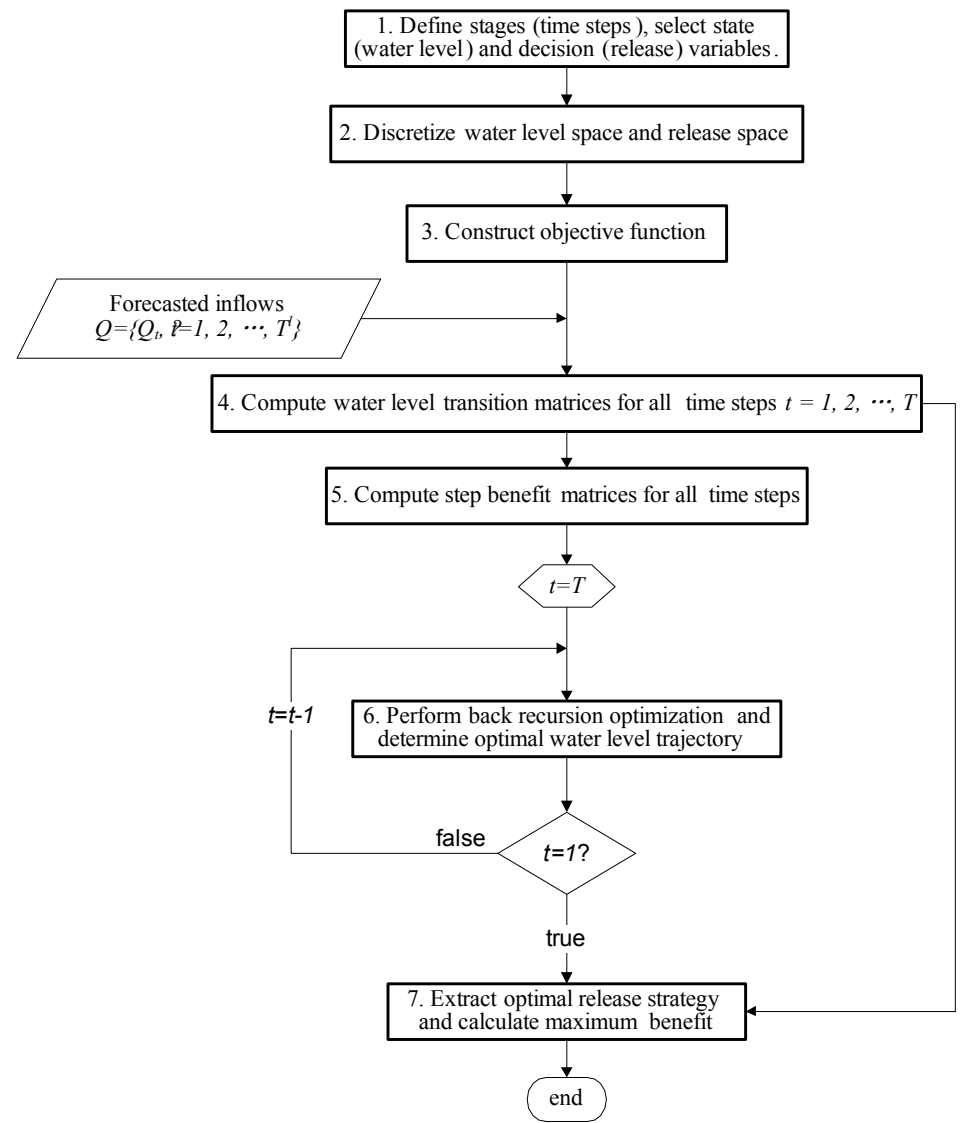

HESSD

3, 3771-3814, 2006

\section{Effect of flow forecasting quality on benefits of reservoir operation}

$X$. Dong et al.

Title Page

Abstract Introduction

Conclusions

References

Tables

Figures

14

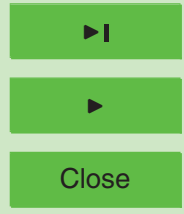

Back

Close

Full Screen / Esc

Fig. 5. Calculation procedure of the Discretized Dynamic Programming (DDP) model.

Printer-friendly Version

Interactive Discussion 


\section{HESSD}

3, 3771-3814, 2006

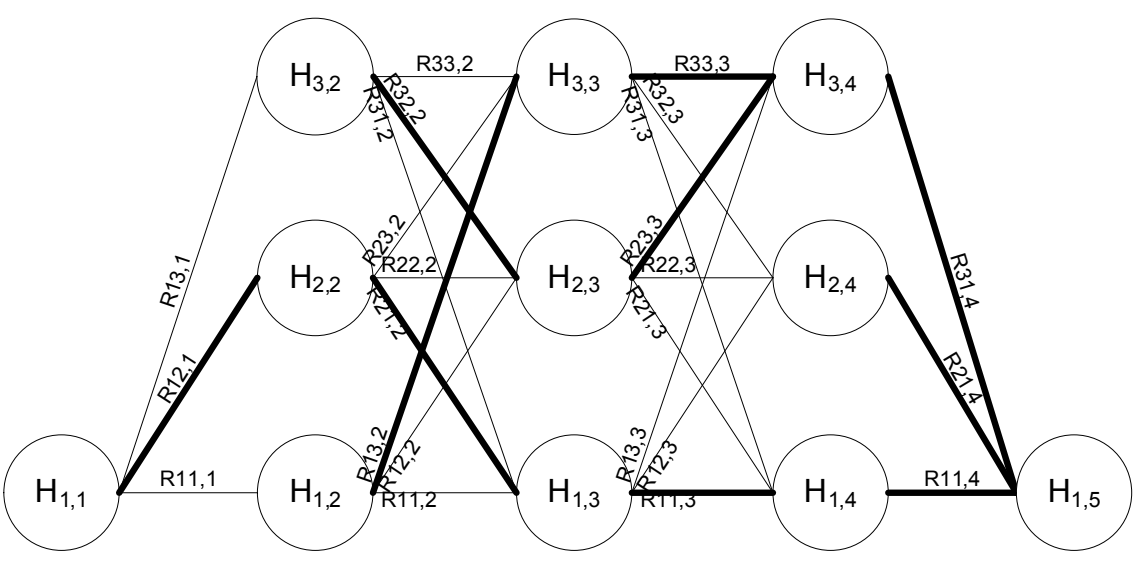

\section{Effect of flow forecasting quality on benefits of reservoir operation}

X. Dong et al.

Title Page

Abstract

Conclusions

Tables

14

4

Back

Full Screen / Esc

Printer-friendly Version 

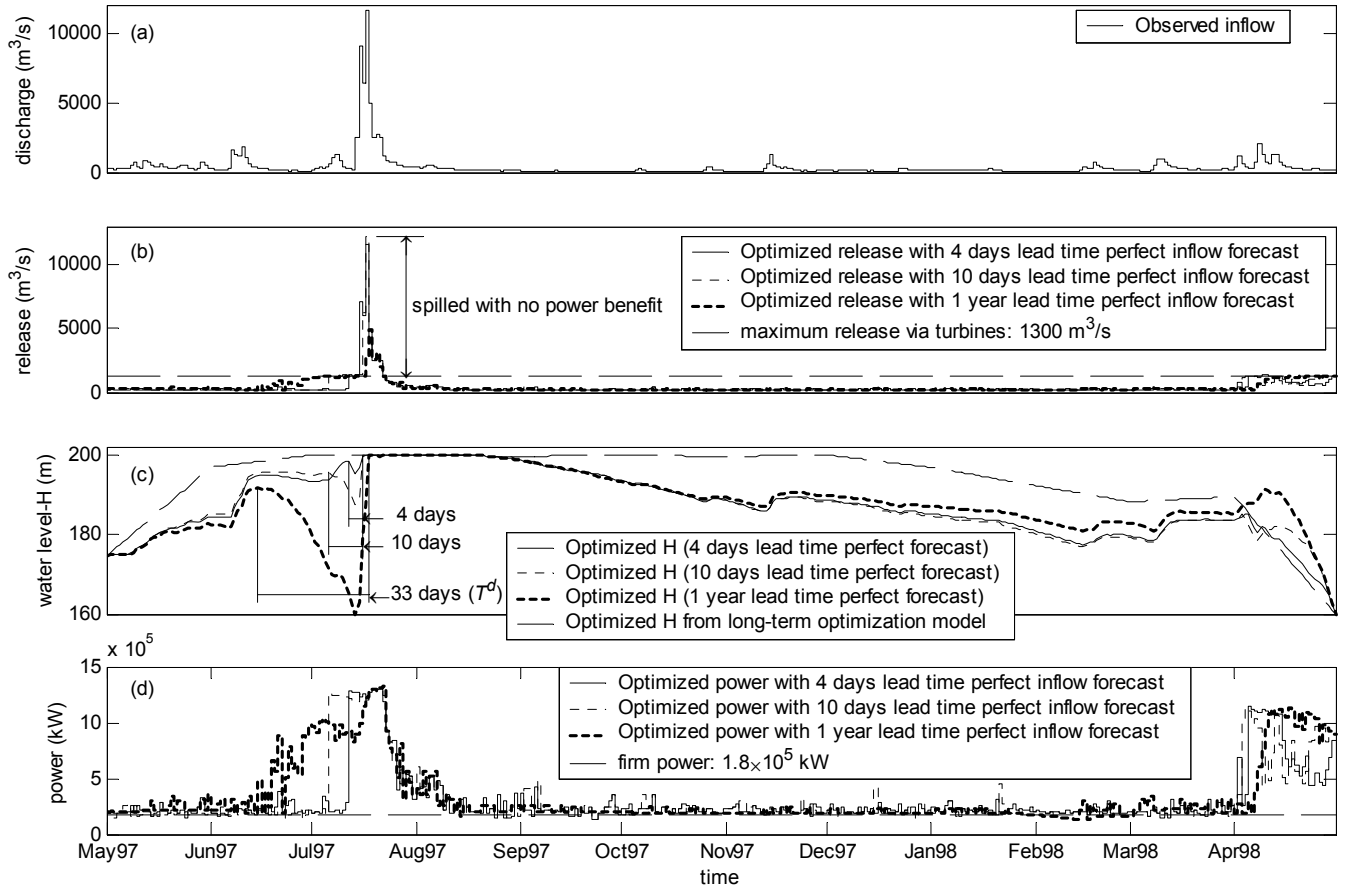

Fig. 7. Optimized operation results under perfect flow forecasts with lead times of 365,10 and 4 days. (a) The observed inflow series of the Geheyan Reservoir in the hydrological year 1997; (b) The optimized releases with 4 days, 10 days and 1 year perfect flow forecasts; (c) The optimized water levels with 4 days, 10 days and 1 year perfect flow forecasts, and optimized water level from long-term optimization model; (d) The optimized power output with 4 days, 10 days and 1 year perfect flow forecasts.

\section{HESSD}

3, 3771-3814, 2006

\section{Effect of flow forecasting quality \\ on benefits of reservoir operation}

X. Dong et al.

\section{Title Page}

\section{Abstract}

Introduction

Conclusions

References

Tables

Figures

14

4

Back

Close

Full Screen / Esc

Printer-friendly Version

Interactive Discussion 


\section{HESSD}

3, 3771-3814, 2006
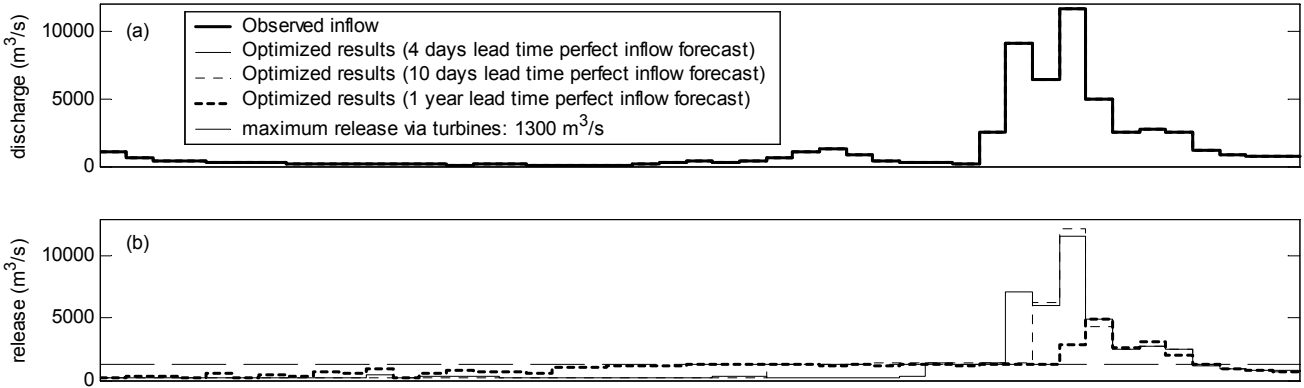

\section{Effect of flow forecasting quality on benefits of reservoir operation}

X. Dong et al.

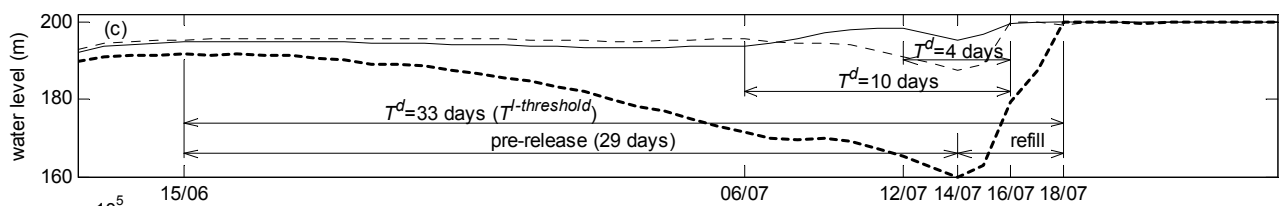

Title Page

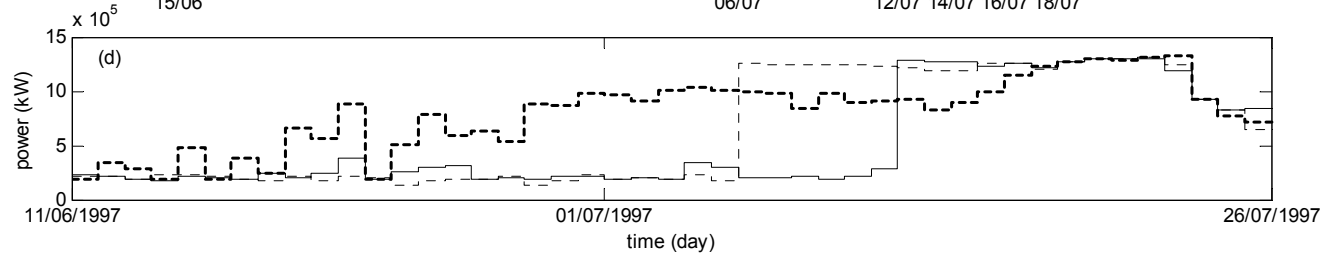

Introduction

Conclusions

References

Tables

Figures

14

$>$ I

4

Back

Close

Full Screen / Esc from Fig. 7).

Printer-friendly Version

Interactive Discussion 


\section{HESSD}

3, 3771-3814, 2006

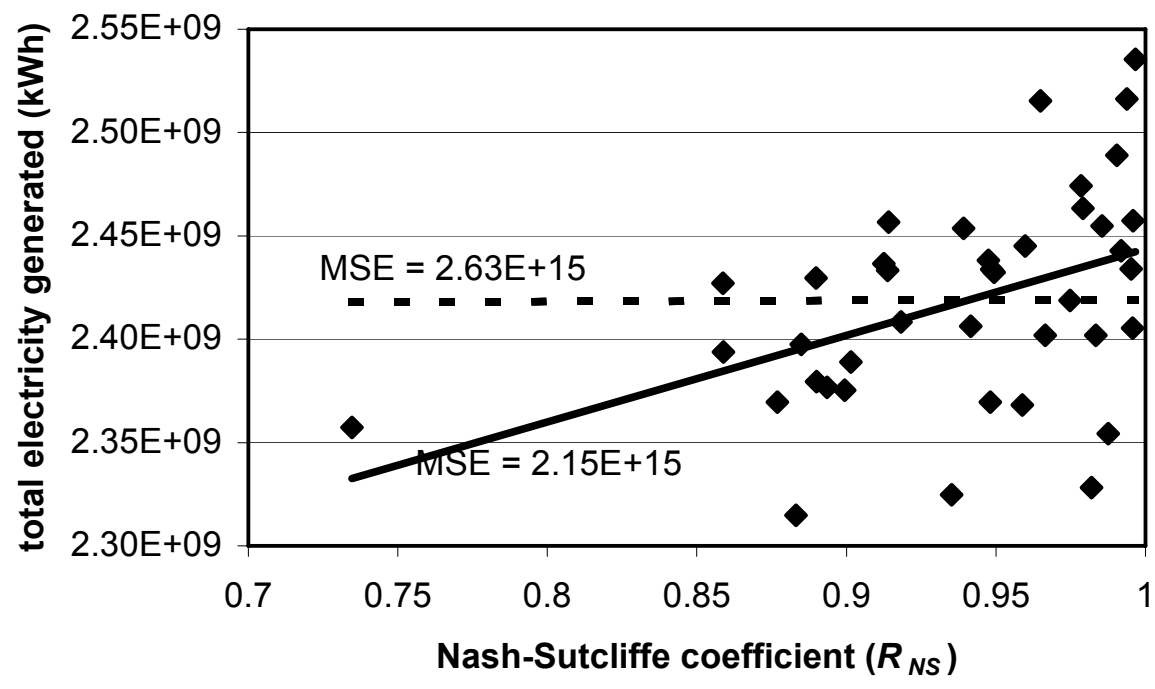

Fig. 9. The relationship between the benefits and the Nash-Sutcliffe coefficient $\left(R_{N S}\right)$ of the forecasted flow series. The straight line is the line fitted to the data (dots) by using a linear equation; the dashed line represents the mean of the data; The MSEs attached are the Mean Squared Errors of these two lines to the data.

\section{Effect of flow forecasting quality on benefits of reservoir operation}

X. Dong et al.

\section{Title Page}

\section{Abstract}

Conclusions

Tables

14

4

Back
Introduction

References

Figures

$\rightarrow$ I

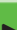

Close

\section{Full Screen / Esc}

Printer-friendly Version

Interactive Discussion 


\section{HESSD}

3, 3771-3814, 2006

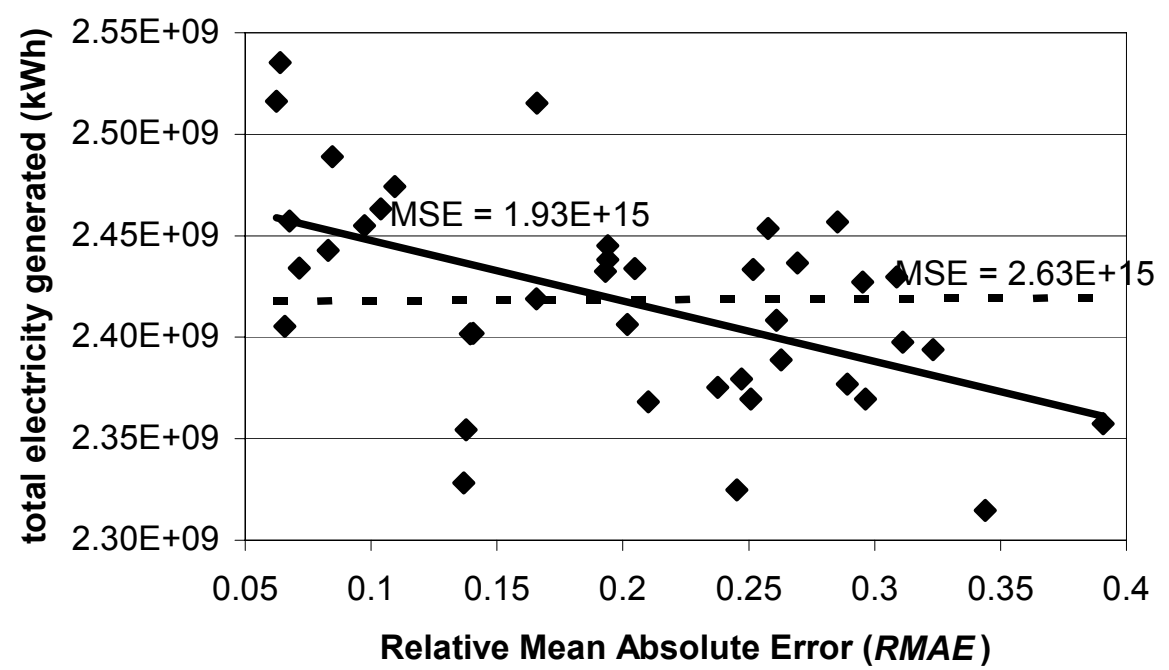

Fig. 10. The relationship between the benefits and the relative mean absolute error of the forecasted flow series. The straight line is the line fitted to the data (dots) by using a linear equation; the dashed line represents the mean of the data; The MSEs attached are the Mean Squared Errors of these two lines to the data.

\section{Effect of flow forecasting quality on benefits of reservoir operation}

X. Dong et al.

\section{Title Page}

Abstract

Introduction

Conclusions

References

Tables

Figures

14

$\rightarrow$

4

Back

Close

Full Screen / Esc

Printer-friendly Version

Interactive Discussion 


\section{HESSD}

3, 3771-3814, 2006

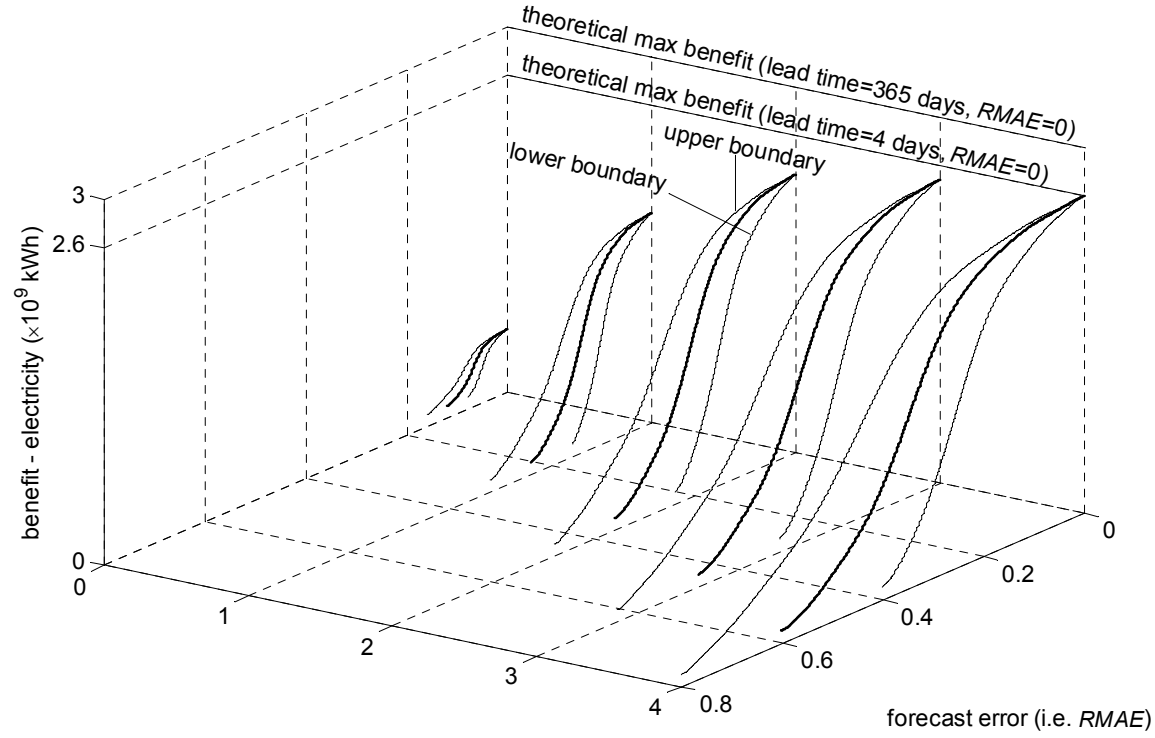

lead time (day)

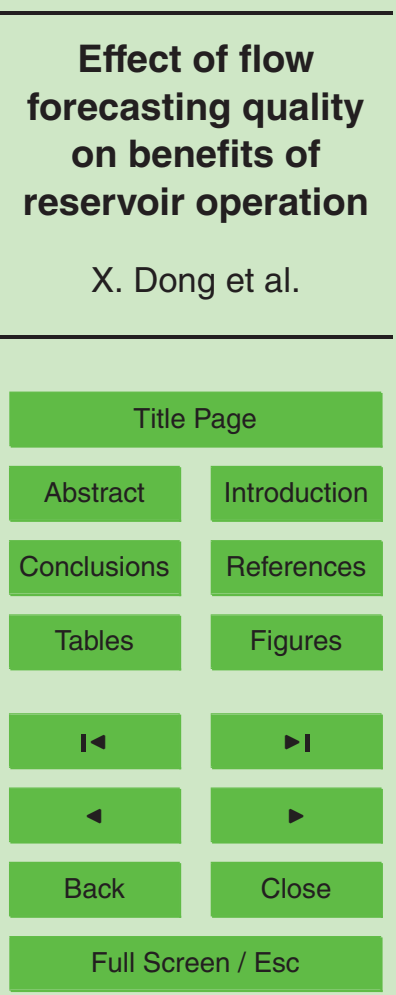

Printer-friendly Version 